\title{
LOUIS XI ET LE PARTAGE FAMILIAL DE LA DÉVOTION
}

\author{
Yannick Frizet - LA3M UMR 7298 - Université d'Aix-Marseille CNRS
}

Dans le cas du chef de la maison de France, la notion de «famille » recouvrait un environnement assez large. À travers ses nombreuses lettres missives ${ }^{1}$, ses ordonnances ${ }^{2}$ et les comptes de son $\mathrm{Hôtel}^{3}$, corpus toutefois lacunaire, Louis XI (1461-1483) a laissé nombre d'indices sur sa conception de la famille ; et dans certains cas, l'existence de liens familiaux était largement soumise à sa subjectivité. Conformément aux Grandes Chroniques de France, le roi considérait les Mérovingiens et les Carolingiens comme ses «prédécesseurs » ${ }^{4}$ sur le trône de France et donc ses ancêtres biologiques. Dans ce cas de famille "légendaire », l'affirmation allait de pair avec une quête de légitimité et parfois même une revendication de droits ${ }^{5}$. Parmi les vivants aussi, les « parents » du roi pouvaient se recruter quelquefois assez loin. Ainsi, Louis XI donnait-il à Laurent de Médicis du «Mon cousin ${ }^{6}$ ou mieux encore la formule «carissimi consanguinei nostri $»^{7}$, produisant un lien du sang qui n'existait pas. De même, le duc de Milan Francesco Sforza apparaissait-il conjointement comme «fratello et cosino $»^{8}$. Plus proche de lui, la fille de sa sœur Yolande, Louise de Savoie, était considérée non pas comme sa nièce mais sa « fille ${ }^{9}$. Quant au futur époux de Louise recherché par le roi, le seigneur de Château-Guyon, il deviendrait par mariage non pas son fils mais son «neveu ${ }^{10}$. Face à une conception familiale difficile à délimiter, parfois assise sur des considérations politiques, j'ai choisi de revenir à une notion plus objective. Son père Charles VII, son oncle maternel René d'Anjou-Provence, sa seconde et dernière épouse Charlotte de Savoie et le seul fils qui leur survivrait, le futur Charles VIII, constituent la parentèle la plus proche, la plus indéniable, de Louis XI, permettant d'aborder le personnage sous l'angle des rapports familiaux.

La question du traitement réservé à ces quatre proches par Louis XI, personnage si indépendant, si retors, si pleinement absorbé par sa fonction de monarque, a déjà bien intéressé l'historiographie ${ }^{11}$. Il s'agira ici de rappeler l'évolution, dans le temps et les circonstances, du comportement royal envers ces quatre personnalités qui ne manquaient pas d'assister, de participer

\footnotetext{
${ }^{1}$ J. Vaesen et E. Charavay, Lettres de Louis XI, roi de France, publiées d'après les originaux, pour la Société de l'Histoire de France, t. I à XI, Paris, 1883-1909. On pourra consulter une sélection de ces lettres dans H. Dubois, Louis XI, Lettres choisies, Paris, 1996.

${ }^{2}$ Comte de Pastoret, Ordonnances des rois de France de la troisième race, recueillies par ordre chronologique, t.XV à XIX, Paris, 1811- 18.. Pour la province de Dauphiné : E. Pilot de Thorey, Catalogue des actes du dauphin Louis II devenu le roi de France Louis XI relatifs à l'administration du Dauphiné, Grenoble, 1899, 3 vol.

${ }^{3}$ M.L. Douët-D'Arcq, Comptes de l'hôtel des rois de France aux XIVe et XVe siècles, pour la Société de l'Histoire de France, Paris, 1865.

${ }^{4}$ Lettres, t.VI, p.77-79, au Sacré Collège, 22 juil. 1476 : «predecessor noster Pippinus, dum vixit Francorum rex ». Louis XI tenait à maintenir le patronage sur l'abbaye de Prum, située dans l'Empire.

5 Ibidem, t.VII, p.36-44, à l'empereur Frédéric, avril 1478 : «Karoli magni, et aliorum progenitorum nostrorum Romanorum regum, a quibus imperium ad modernos imperatores collapsum est $\gg$. Il revendiquait non seulement Charlemagne pour ancêtre mais aussi la partie orientale de son empire.

${ }^{6}$ Ibid., t.X, n¹859, p.64-65, 3 fév. 1483.

${ }^{7}$ Ibid., t.VII, p.177-179, sept. 1478.

${ }^{8}$ Ibid., t.III, p.95-97, au cardinal d'Estouteville, le 24 sept. 1466. Dans les deux cas le roi s'adressait à des chefs d'Etat alliés et amis, dont il soutenait activement la politique.

${ }^{9}$ Il est vrai que Yolande était morte depuis peu et que les barons savoyards entendaient mettre fin à la forte influence française (P.-R. Gaussin, Louis XI, roi méconnu, Paris, 1988, p.337-339).

${ }^{10}$ Lettres, t.VIII, p.43-44 et p.43, n.2, à l'évêque d'Albi, 29 juin 1479.

${ }^{11}$ Je renvoie aux ouvrages les plus récents : J. Favier, Louis XI, Paris, 2001 ; J. Heers, Louis XI. Le métier de roi, Paris, 1999 ; P. Murray Kendall, Louis XI, Londres, 1971, Paris, 1974.
} 
ou de pâtir de ses incessants et ambitieux projets. Pour retracer ces rapports dans leur complexité, je recourrai le plus souvent aux lettres et aux actes du roi. Dans le cas de Louis XI, la confrontation des unes et des autres apparaît nécessaire pour approcher la réalité du personnage, de même que les points de vue apportés par les chroniqueurs contemporains tels que Philippe de Commynes ou Thomas Basin ${ }^{12}$.

Louis XI s'est distingué par sa profonde et insatiable piété. Il s'est montré l'un des plus grands donateurs de son temps, pourvoyant les institutions religieuses, sa vie durant, de terres, de revenus, d'ouvrages, de privilèges, de protection, pour susciter les prières en sa faveur et celle de l'État. Outre la «glorieuse Vierge », nombreux sont les saints devant lesquels il se présentait, physiquement, à travers ses libéralités, ou par le biais des «images ${ }^{13}$ qu'il leur consacrait en abondance, afin d'obtenir leur intercession constante auprès de Dieu ou de son Fils. D'une certaine façon, Dieu a bien souvent «entendu parler» de Louis XI, mais se pose la question de la participation de la famille à ses actes de dévotion. Lui qui invoquait saint Hubert pour la santé de ses chiens ${ }^{14}$, associait-il ses proches parents à la piété royale? Il sera ainsi question de la transcription dans le domaine de la piété des éventuelles affinités ou antagonismes qui auront été relevés précédemment. Il s'est formé autour du roi une certaine communion familiale de prière, qui se prête à l'analyse par le biais des « images » qu'elle a produites et qui révèlent non seulement la nature de la collaboration dévotionnelle mais aussi d'éventuelles interactions entre ses membres. Dans ces « images » que Louis XI donnait aux églises et qu'il lui arrivait de concevoir, quelle place tenait sa famille naturelle ? Cette question revient à examiner avec qui, où et pourquoi Louis XI choisissait-il de prier, ou encore pour qui le faisait-il. Finalement, le premier «très chrétien roi de France » priait-il ou faisait-il prier pour le salut de son père, de son oncle, de son épouse, comme il le faisait immanquablement pour l'héritier de la couronne ? Tels sont les enjeux couverts par la notion de «partage familial » de la dévotion.

\section{Maturation du sentiment filial pour Charles VII}

A partir de 1440, le jeune dauphin Louis commençait à concevoir de l'amertume envers son père, Charles VII. Dès février, il se laissait convaincre par quelques grands de participer à la Praguerie, rapidement maîtrisée par le Victorieux. Bénéficiant des circonstances atténuantes de son jeune âge de 17 ans $^{15}$, il obtenait par la suite l'administration du Dauphiné, comme il le réclamait ${ }^{16}$. Il prit assez tôt en aversion tous ceux qui avaient l'oreille de son père ${ }^{17}$. Une telle force d'opposition croissante au sein de la cour de France devenait insoutenable et en janvier 1447 Louis se voyait chassé par son père dans la province du Dauphiné, aux confins alpestres du royaume. Charles VII avait précisé qu'il ne pourrait réintégrer la cour qu'au terme de quatre mois ${ }^{18}$. Louis ne consentirait jamais à revenir.

\footnotetext{
${ }^{12}$ B. de Mandrot, Mémoires de Philippe de Commynes, Paris, 1901, 2 vol. Ch. Samaran, Thomas Basin. Histoire de Louis XI, Paris, 1963, 2 vol.

${ }^{13}$ Je renvoie ici à la notion d' «images-objets » telle que développée par J. Baschet, L'iconographie médiévale, Paris, 2008, p.25-64.

${ }^{14}$ A. Gandilhon, «Contribution à l'histoire de la vie privée et de la Cour de Louis XI (suite) », dans Mémoires de la Société littéraire et scientifique du Cher (1906-1907), $4^{\mathrm{e}}$ série, $21^{\mathrm{e}}$ vol., Bourges, Paris, 1907, p.46 et n.5. Voir aussi A. Lapeyre, Louis XI mécène dans le domaine de l'orfèvrerie religieuse, Paris, 1986, p.18 et n.3.

${ }^{15}$ Favier, op. cit, 2001, p.84-91.

${ }^{16}$ Lettres choisies, ${ }^{\circ} 1$, p.47-49. La date de 1444 paraît erronée, les lettres se situant au terme de la Praguerie, soit en 1440. Charles VII lui confiait cette province comme un expédiant le 28 juillet 1440 (B.n.F. ms. fr. 6967, fol. 46). Le dauphin ne s'en sentirait pas moins mésestimé par la suite (Favier, op. cit., 2001, p.95-108).

${ }^{17}$ Comme Agnès Sorel (B.n.F. ms. fr. 6967, fol. 84. Favier, op. cit., 2001, p.113-115), son conseiller René d'Anjou ou Marguerite, l'épouse écossaise que son père lui avait donnée en juin 1436 et qui décéderait en 1444 (Commynes, t.II, p.85, n.2 et Favier, op. cit., p.75-78, 111).

${ }^{18}$ Murray Kendall, op. cit., 1971, p.48.
} 
En Dauphiné, il saisissait l'occasion d'une province dont le statut ouvrait de bonnes perspectives d'indépendance ${ }^{19}$ pour s'affirmer à 24 ans comme le souverain d'un petit État au bord de la sécession. Il négociait en 1449 avec l'un des princes voisins, le duc de Savoie, la main de sa fille $^{20}$. Contre l'avis de Charles VII, qui ne saurait contrer sa détermination, Louis prenait pour seconde épouse Charlotte de Savoie. Néanmoins, l'isolement du bouillonnant dauphin se trouvait accentué par la confiscation de certains de ses revenus dans le royaume ${ }^{21}$. Depuis son arrivée en Dauphiné, Louis répondait au courroux et aux intimidations de son père par une diplomatie policée. Il recourait d'autant plus aux déclarations d'intentions ${ }^{22}$, que la naissance d'un frère, Charles, faisait peser sur lui la menace d'une exhérédation ${ }^{23}$. En 1452, le roi avait à répondre devant le pape des agissements violents du dauphin en Comtat Venaissin. Il faudrait la médiation de deux cardinaux, le légat en France d'Estouteville et le légat d'Avignon de Foix, pour apaiser la tension dont le turbulent héritier de France avait été responsable ${ }^{24}$.

En 1453, Louis répondait favorablement à l'invitation de son père à participer à une expédition dans le Milanais conduite par René d'Anjou. Malgré son réel investissement ${ }^{25}$ l'entreprise tourna court, notamment en raison de divergences tactiques avec René. Toute collaboration avec le dauphin de Viennois s'avérait malaisée. Alors que Louis usurpait tous les pouvoirs dauphinois au détriment de son père, celui-ci commandait un ultime affrontement militaire ${ }^{26}$.

Louis, à trente-trois ans, se voyait acculé à solliciter hébergement et entretien chez le pire ennemi de son père. Il n'interrompait cependant pas les courriers ni les ambassades empreintes de piété filiale, tandis que Charles VII publiait dans le royaume une exhortation à la méfiance vis-à-vis du dauphin ${ }^{27}$. Aucune des formules scripturaires de Louis ne parvenait à rasséréner Charles VII à son sujet ${ }^{28}$. Lorsqu'il abandonnait le registre des suppliques, Louis informait joyeusement Charles VII de sa future paternité. Ainsi pour la naissance de son premier fils, Joachim, il écrivait à son père le 27 juillet 1459 en ces termes : " il a pleu à nostre benoist Createur et à la glorieuse Vierge sa mere delivrer ce jourduy au matin ma femme d'un beau filz». Charles VII faisait réponse une dizaine de jours plus tard par des lettres de félicitations ${ }^{29}$. Mais le nouveau-né ne survivrait pas audelà de quelques mois ${ }^{30}$. En décembre 1459, la dauphine était encore enceinte, et Louis informait son père par lettres que « la chose est seure ; car elle [Charlotte] a ja senti par plusieurs fois bouger son enfant, de quoy je sçay serés bien joyeux $»^{31}$. L'enfant serait une fille, née-morte en mai 1460 et

\footnotetext{
${ }^{19}$ Sur le statut atypique du Dauphiné on se rapportera à Favier, op. cit., 2001, p.24-26 et 132, 175 et P. de Thorey, op . cit., t.II, n.1, p.370-372.

${ }^{20}$ P. de Thorey, op. cit., t.I, n'850, p.321-323, et n.1, p.321-322.

${ }^{21}$ Charles VII reprit des châtellenies à Louis en Rouergue : P. de Thorey, op. cit., t.II, n 1903, p.391, 3 juillet 1452. Louis les réclamait encore le 6 fév. 1456 ( ${ }^{\circ} 1912$, p.395).

${ }^{22}$ Voir P. de Thorey, op. cit., t.I, n ${ }^{\circ} 979$ et p.359, n.1, au sujet du voyage de Guillaume de Coursillon en oct. 1452.

${ }^{23}$ B.n.F. ms. fr 6967, fol 84. Basin, op. cit., t.I, p.5 et n.4. Charles de France naquit le 28 déc. 1446.

${ }^{24}$ Lettres, t.I, n56, p.240-241, 10 nov. 1452 ; n57, p.241-242, 22 nov. 1452.

${ }^{25}$ B.n.F. ms. fr. 6966, fol. 369, 17 août 1453.

${ }^{26}$ Entre mars et juillet 1456, Louis envoyait au moins quatre ambassades à Charles VII, pour le convaincre de ses bonnes intentions La première ambassade aurait lieu au début du printemps 1456 (Murray Kendall, op. cit., 1971, p.6364), la deuxième en avril 1456 (P. de Thorey, op. cit., t.I, p.359, n.1), la troisième après le 28 mai 1456 (Lettres, t.I, $\mathrm{n}^{\circ} 55$, p.75-76) et la quatrième après le 21 juillet 1456 (Lettres, t.I, n56, p.76-77). Par la troisième, il demandait au roi, lui le récalcitrant de toujours, de l' " avoir et tenir tousjours en [sa] bonne grace, ensemble [lui] mander et commander [ses] bons plaisirs, pour iceulx faire et acomplir à [son] povair ». Le 30 août 1456, à l'approche de l'armée française, le dauphin trouvait refuge dans les terres méridionales du duc de Bourgogne Philippe le Bon, sous couvert, notamment, de préparation à la croisade (Murray Kendall, op. cit., 1971, p.66 ; Lettres, t.I, n57, p.77-78 : au roi de France, SaintClaude, 31 août 1456 : «nostre saint pere le pappe m'en a requis et que je suis gonfalonnier de l'esglise et en fiz le serment par vostre commandement »; voir aussi n 58, p.78-79).

${ }^{27}$ Lettres, t.I, nº70, p.263-265, 14 sept. 1456.

${ }^{27}$ Basin, op. cit., t.I, p.5 et n.4. Charles de France naquit le 28 déc. 1446.

${ }^{28}$ Dès décembre 1456 on le soupçonnait d'avoir fomenté une tentative d'enlèvement du roi (Heers, op. cit., 1999, p.49).

${ }^{29}$ Lettres, t.I, n ${ }^{\circ}$ LXXVIII, p.104-105, au roi de France, Notre-Dame de Hal. Pour la réponse de Charles VII, en date du

7 août, voir p.104, n.2.

${ }^{30}$ Heers, op. cit., 1999, p.48.

${ }^{31}$ Lettres, t.I, n`87, p.116-117, 13 décembre 1459. Louis donnait à son père la formule : « mon trés redoubté seigneur ».
} 
prénommée Louise. Malgré ces échanges sous l'apparence de la cordialité, Louis continuait d'inspirer à son père une méfiance qui confinait à la terreur ${ }^{32}$.

Une fois assuré que son heure était arrivée, il réintégrait le royaume pour prendre le trône à trente-huit ans passés. Sur la route qui le conduisait à Reims, il faisait célébrer à Avesnes, en Hainaut, une messe funéraire en la mémoire de son père. Il semble avoir limité le faste du protocole $^{33}$, bien que les chroniqueurs se contredissent sur l'ampleur qu'il souhaitait donner à la cérémonie funéraire $^{34}$. On s'accorde à croire qu'il se débarrassa rapidement de ses habits de deuil pour s'en aller chasser le jour même de la cérémonie ${ }^{35}$. Quoi qu'en aient pensé les contemporains, Louis semble n'avoir pas contrevenu aux usages qui voulaient, conformément à la loi de la continuité de la monarchie, que le nouveau roi ne portât pas le deuil du roi défunt ${ }^{36}$. Une fois sacré roi dans la cathédrale de Reims le 15 août $1461^{37}$, il ne restait plus à Louis XI qu'à prendre en main toutes les affaires de son père et à adopter une posture devant sa mémoire. En premier lieu, il allait se recueillir devant sa sépulture à l'abbaye royale de Saint-Denis. Alors eut lieu une scène qui, selon Thomas Basin, outragea la mémoire de Charles VII. Un évêque italien de la suite de Louis présenta une lettre d'absolution de celui qui était l'instigateur de la Pragmatique Sanction, comme s'il eut été de son vivant excommunié par l'Eglise ${ }^{38}$. Cet incident a-t-il pu échapper à la volonté de Louis XI ? Probablement pas. À l'égard de la mémoire de Charles VII, les écrits de Louis XI ne laissent transparaitre que des formules cordiales mais très convenues telle : «feu nostre très-chier seigneur et pere, cui Dieu pardonne $»^{39}$. En somme les mots de Louis ne reflètent presque pas le clivage entre le dauphin plein d'amertume qu'il était et le roi de France assouvi qu'il devint. Le vrai Louis XI se perçoit dans les actes.

Le fait est bien connu, le nouveau roi limogeait une bonne partie des conseillers et officiers de son père, pour les remplacer par des fidèles ${ }^{40}$, ce qui engendrait la sédition du «Bien public » en 1465. Il devait par la suite revenir sur cette décision et en réintégrer un grand nombre. Au point de vue strictement gouvernemental, il reprenait peu ou prou la ligne de son père ${ }^{41}$, s'en distinguait néanmoins par son impérialisme constant, son omniprésence et ses rapports à l'Eglise, soit des factorielles de son propre caractère. Les enfants naturels que Charles VII avait eus avec Agnès Sorel, favorite pourtant haïe de Louis de son vivant, trouvaient plus que grâce aux yeux de leur demi-frère ${ }^{42}$.

\footnotetext{
${ }^{32}$ Le dauphin avait probablement des informateurs à la cour, notamment la demoiselle de Villequier, une des maîtresses du roi (Lettres choisies, $\mathrm{n}^{\circ} 40$, p.78, 30 août, prob. 1460). Charles VII mourait le 22 juillet 1461, convaincu d'être empoisonné par les suppôts de son fils (Commynes, t.II, p.41-42 ; Favier, op. cit., 2001, p.187).

${ }^{33}$ Gandilhon, art. cit, 1906, p.32 : à Jean Juvénal des Ursins, archevêque de Reims, qui s'était présenté à Avesnes, pour l'accueillir en ces circonstances, il conseillait, par deux fois, d'être bref. Notons qu'il lui serait habituel, son règne durant, de se mettre en retrait devant les grandes solennités civiles.

${ }^{34}$ Basin, t.I, p.11-13, parle, au sujet de la messe funéraire d' « Avesnes-le-Comte », de « la mesquinerie [qui] marquait assez le peu d'affection qu'il avait eue pour lui de son vivant. » Mais il est vrai que Basin était par nature hostile à Louis XI. Voir p.13 n.1 où il est rapporté qu'à l'inverse, Mathieu d'Escouchy, dans Chroniques, t.II, p.422-423, et Jacques du Clercq, dans Mémoires, 1. IV, chap. XXX, p.135-136, rapportent qu'il « fist incontinent ung beau et honnourable service et obsèque pour l'âme de sondit feu père. »

${ }^{35}$ Gandilhon, art. cit, 1906, p.50-51.

${ }^{36}$ C. Beaudet, Histoire des institutions jusqu'à la Révolution de 1789, Centre de publications universitaires, Vélizy, 1996, p.175-176.

${ }^{37}$ Favier, op. cit., 2001, p.192.

${ }^{38}$ Basin, op. cit., t.I, p.23-25.

${ }^{39}$ Formule adoptée dès les premières lettres patentes de Louis XI (Ordonnances, t.XV, p.1, 30 juillet 1461) et régulièrement reprise, à l'identique ou avec quelques variantes, comme dans Lettres, t.VII, p.184-186, au Parlement, 4 oct. 1478 : «feu nostre trés chier seigneur et pere, que Dieu absoille » ou encore dans Lettres, t.IX, n 1657, p.114-116, aux gens des comptes à Paris, 18 déc. 1481 .

${ }^{40}$ Basin, op. cit., t.I, p.9-11, 33-35.

${ }^{41}$ Commynes, t.II, p.48 et n.3, p.48-49 ; C. Gauvard, La France au Moyen Age du Ve au XVe siècle, Paris, 1996, p.481491, 503-505).

${ }^{42}$ Louis XI se montrait très attentif à leur éducation et leur situation matrimoniale. Il arrangeait pour Jeanne en 1461 un mariage avec Antoine de Bueil, fils héritier de l'amiral de France (Lettres, ${ }^{\circ} 1609$, t.IX, p.55-56 ; sur Jeanne, voir p.55, n.2 et p.56, n.1) et donnait la main de leur fille Marie à Jean de Bruges. En 1462 il faisait faire à Charlotte un beau mariage avec Jacques de Brézé. A Catherine, petite-fille naturelle de Charles VII par sa fille Marie, il faisait épouser
} 
Des «œuvres » de Charles VII Louis XI semble avoir prit soin. Nombreuses sont les ordonnances où le nouveau roi confirmait des privilèges ou des dons accordés aux établissements religieux par son père ${ }^{43}$. Dès 1461, il confirmait les concessions financières promises par Charles VII pour la reconstruction des églises de Notre-Dame de Pontoise, Notre-Dame de Montfort et Notre-Dame de Cléry ${ }^{44}$. Dans cette dernière, dans le duché vassal d'Orléans, il élirait sépulture, plutôt qu'à l'abbaye de Saint-Denis, rompant strictement avec une tradition non seulement paternelle mais séculaire ${ }^{45}$. Mais en général, la piété de Louis XI s'inscrivait dans la tradition française. Dès le delphinat, soustrait à l'autorité paternelle, il s'attachait à une abbaye provençale qui avait fait l'objet de pèlerinages et d'abondantes offrandes des rois capétiens et valois. À la suite de ses deux parents ${ }^{46}$, Louis accomplissait le pèlerinage de Saint-Maximin - la Sainte-Baume dès 1447 et poursuivrait ses libéralités jusqu'après l'union du comté de Provence à la France. De même, la cathédrale d'Evreux voyait Louis XI maintenir les libéralités de Charles VI ${ }^{47}$. La même attitude se remarque avec le sanctuaire dauphinois de Notre-Dame d'Embrun, appelée aussi « Nostre-Dame des Roys ${ }^{48}$. Il n'était que dauphin de Viennois lorsqu'il se présentait en pèlerin devant le portail des Trois Rois de la cathédrale d'Embrun en $1449^{49}$. Là encore son avènement le conforterait dans sa dévotion, en appelant même à la mémoire de son père. En mars 1477, le général des finances du Dauphiné exigeait de son receveur général le versement d'une somme de cinq-cents livres tournois par an «à ceux de l'église d'Ambrun » pour les deux années à venir. L'objet du don était explicité plus loin : «et ledict prix, pour un service qu'ils font à l'intension du feu roy Charles ; en insinuant l'estat qui vous en a esté fait par le Roy, nostre dict sire. » On voit ainsi Louis XI, à un moment où le duché de Bourgogne, après la mort du Téméraire, s'apprêtait à réintégrer la couronne, honorer la mémoire de son père à Embrun. Mais l'initiative en revenait à Charles VII lui-même, qui l'avait requis de son fils ${ }^{50}$. Ce ne sont pas les seuls exemples pour lesquels Louis mettait ses pas de pèlerin dans ceux de son père. En 1472, il renouait avec le sanctuaire de Notre-Dame de l'Epine, en

son capitaine général des francs-archers Antoine de Chourses en 1476 (P.-R. Gaussin, « Les conseillers de Louis XI (1461-1483) », La France de la fin du XVe siècle. Renouveau et apogée, B. Chevalier et Ph. Contamine (dir.), Paris, 1985, p.109). et prodiguait à ses deux sœurs Marguerite et Gillette bien des attentions (Heers, op. cit., 1999, p.227-228). D'après le corpus disponible à ce jour, nulle lettre de Louis XI n'est plus empreinte d'affection envers ses proches que la missive datée de juillet 1477 où il prescrivait à la gouvernante de ses « deux nièces » de Coëtivy de leur appliquer un régime alimentaire particulier (Lettres choisies, $\mathrm{n}^{\circ} 472$, p.443-444, à leur gouvernante $\mathrm{M}^{\mathrm{me}}$ de la Bellière, 28 juillet 1477).

${ }^{43}$ Ordonnances des rois de France, vol. XV à XIX pour le règne de Louis XI. Pour une approche plus synthétique, je recourrai à la Table chronologique des ordonnances..., par J.M. Pardessus, Paris, 1847. Louis XI demeurait dans la tradition de Charles VII, lequel s'était déjà montré particulièrement bienveillant envers les célestins (par exemple cat. p.364, 1440 ; cat. p.388-389, 1459, et passim), envers les chartreux (cat. p.376, 1449), les hospitaliers de Saint-Jean-deJérusalem (cat. p.383, 1453 et passim), et quelques grands sanctuaires comme Saint-Martin de Tours (cat. p.350, 1423 ; cat. p.368, 1444 ; et passim), Saint-Denis (cat. p.380, 1451 ; et passim) ou Saint-Antoine-en-Viennois (cat. p.371, 1446 ; et passim).

${ }^{44}$ Bulletin de la Société nationale des Antiquaires de France, séance du 23 juin 1965, Paris, 1965, p.156-161.

${ }^{45}$ Favier, op. cit., 2001, p.903-904.

${ }^{46}$ Faillon, Monuments inédits sur l'apostolat de sainte Marie-Madeleine en Provence, 2 vol, 1848, t.I, p.818 pour le pèlerinage de Louis IX ; p.944-950 pour celui de Philippe de Valois ; p.966 pour Jean II ; p.977 pour Charles VI, grandpère de Louis XI ; p.996, pour Marie de Valois, mère de Louis XI ; 999 pour Charles VII ; pour Marie de Valois voir aussi t.II, p.1131-1138. Je me permets de signaler que les rapports entre Louis XI et la Provence font l'objet de mon doctorat en cours à l'université d'Aix-Marseille I sous le titre : Munificence et stratégie de Louis XI dans l'aire provençale (1440-1483).

${ }^{47}$ F. Gatouillat, "Les peintres-verriers au service de Louis XI à la cathédrale d'Evreux », dans L'artiste et le commanditaire aux derniers siècles du Moyen Age (XIIIe-XVIe siècles), F. Joubert (dir.), coll. Cultures et Civilisations médiévales, XXIV, Paris, 2001, p.211.

${ }^{48}$ M. Fornier, Histoire générale des Alpes maritimes ou cottiènes et particulière de leur métropolitaine Ambrun, continuation par R. Juvénis et A. Albert, Paris, Gap, 1890, t.II, p.360.

${ }^{49}$ P.M. Guillaume, « Louis XI à Embrun », Bull. de la Société d'Etudes des Hautes-Alpes, Gap, 1882, p.29-35.

${ }^{50}$ Lettres du 23 mars 1477, donnée par Fornier, op. cit., t.II, p.362-364. Cette offrande remontait à 1471 mais on ne peut se prononcer sur une éventuelle référence à Charles VII dès alors. Voir Lettres, t.IV, p.308-309 et p.309 n.1 et 2, 26 mars 1472 où l'on précise qu'une oblation sera faite « en ladicte eglise, devant l'image Nostre Dame des Trois Roys ».

Frizet Yannick

Page 5

$09 / 06 / 2019$ 
Champagne, où père et fils avaient conjointement pèleriné à l'époque ou Charles VII présentait le dauphin à travers le royaume ${ }^{51}$. À Saint-Martin de Tours, ses bienfaits n'étaient pas sans référence à ceux de son père. À partir de juillet 1478 il concevait d'offrir une nouvelle grille pour protéger la châsse de saint Martin. La grille de fer serait donc remplacée par une grille d'argent, afin de mieux correspondre aux matériaux d'or et pierres précieuses de la châsse donnée par Charles VII ${ }^{52}$.

A partir de l'automne 1479, Louis XI apparaissait à ses contemporains comme un roi malade ${ }^{53}$. Sa piété, déjà implacable, redoublait dans l'espoir d'obtenir une guérison. Avec les emprunts de reliques illustres, le recours aux saints ermites, les prières pour l'âme de son père appartiennent aux ultimes moyens de salut d'un roi en déchéance physique jusqu'à sa mort en 1483. En 1479, à SaintLéonard de Noblat, en Limousin, il évoquait la mémoire de son passage avec Charles VII quarante ans plus tôt, en demandant une procession aux religieux. C'était favoriser une église que son père avait jadis gratifié d'une châsse ${ }^{54}$. Il fondait en 1480 une messe quotidienne dans la chapelle NotreDame de l'église de Compiègne, en Champagne, "pour la prospérité de nous et de notre royaume et le salut des âmes de feu notre très cher seigneur et père, que Dieu absolve, de nos autres prédécesseurs, de nous et de nos successeurs ». Une rente de 60 1.t. assurerait l'entretien des religieux affectés à ce service ${ }^{55}$. En duché de Bourgogne, à l'abbaye de Saint-Claude, il offrait en mars 1482 les images de ses successeurs les rois de France. Les statuettes en argent, comprenant naturellement celle de Charles VII, figureraient agenouillées en donateurs et orneraient le maîtreautel de l'abbatiale ${ }^{56}$. Ce souci tardif de renouer avec son ascendant se retrouve à l'automne 1482 du côté de Troyes en Champagne. Louis XI s'était souvenu que l'ermite Jean de Gand, ancien moine de Saint-Claude mort en odeur de sainteté à Troyes, avait révélé à Charles VII sa future victoire sur les Anglais, le retour de la paix au royaume et surtout la naissance d'un fils héritier, luimême. Il faisait en octobre des démarches pour faire rechercher sa tombe par les jacobins de Troyes $^{57}$. La sépulture retrouvée jugée inconvenable, le roi s'occupait de la refaire. Au pape, il demandait pour Jean de Gand une canonisation, au motif que «fist lors ledict hermitte plusieurs belles choses à l'augmentation de nostre foy; et aussy Dieu, nostre createur, à sa requeste et intercession, de beaux miracles ». L'auteur de la prophétie de sa naissance, thaumaturge qui plus est, comptait parmi les intercesseurs divins auxquels Louis XI faisait appel à l'extrémité de sa vie ${ }^{58}$. En décembre, il offrait encore un drap d'or aux jacobins de Troyes pour recouvrir la nouvelle sépulture de l'ermite, vraisemblablement dans leur église ${ }^{59}$.

Outre les statuettes de Saint-Claude, Charles VII n'apparait presque pas sur les images conçues par le commanditaire Louis XI. Sa part dans les prières suscitées directement par son fils reste modeste et concerne quelques provinces comme l'Ile-de-France, la Champagne, le Dauphiné, le Limousin, la Bourgogne et le Hainaut. Plus que par piété filiale, le rappel du père se fait dans le contexte de la commémoration dynastique. Le roi n'implique pas son prédécesseur et père dans sa prière autant que ledit père l'a fait avec son fils Louis. En effet, il existait plusieurs images où Charles VII se montrait priant en pendant du dauphin Louis ${ }^{60}$. De même Louis XI s'exposerait bien

\footnotetext{
${ }^{51}$ S. Cassagnes-Brouquet, Louis XI ou le mécénat bien tempéré, Rennes, 2007, p.192.

${ }^{5}$ Ibidem, p.229-230.

${ }^{53}$ Commynes, t.II, p.33 et n.3.

${ }^{54}$ Lapeyre, op. cit., 1986, p.28, n.1.

${ }^{55}$ Lettres choisies, n506, p.462-463, 18 juillet 1480.

${ }^{56}$ Cassagnes-Brouquet, op. cit., 2007, p.223.

${ }^{57}$ Lettres, t.IX, p.316-317, aux jacobins de Troyes, 13 oct.1482

${ }^{58}$ Ibidem, t.IX, p.317-320, au pape, automne 1482.

${ }^{59}$ Ibid., t.X, n 1830 , p.26-27, aux jacobins de Troyes, 3 déc. 1482.

${ }^{60}$ En Languedoc sur un vitrail de la cathédrale de Toulouse en 1438, en Normandie sur un vitrail de la cathédrale d'Evreux (Lapeyre, op. cit., 1986, p.15 et n.6 et 7) ainsi que sur le panneau du Parlement de Toulouse (S. Chavignon, «La Crucifixion du Parlement de Toulouse », et E. Ravaud et L. Callegari, «La crucifixion du Parlement de Toulouse, un chef-d'œuvre retrouvé ", dans Polychromie secrètes. Autour de la restauration de deux œuvres majeures du XVe siècle toulousain, Musée des Augustins, Toulouse, 2006, p.62-78 et 79-86. Les vitraux semblent relever de l'initiative de Charles VII, ce qui n'est probablement pas le cas pour les enluminures du livre I des Annales du Capitole de Toulouse représentant non pas une scène de dévotion mais les entrées du dauphin dans la ville en 1439, 1442 et 1443.
} 
souvent aux côtés de son fils héritier. Ainsi la communion familiale de piété prend préférablement la forme d'une mise sur l'avenir.

\section{Sauver les apparences avec René d'Anjou}

René n'était pas seulement le frère de la mère de Louis XI Marie d'Anjou, il était aussi un prince apanagé de France et l'un des grands d'Europe par la position stratégique de ses domaines. Pour autant les rapports entre les deux hommes seraient toujours malaisés. Dès le delphinat, le jeune Louis faisait grief à son oncle, de quatorze ans son aîné, d'avoir trop d'ascendant sur Charles VII ${ }^{61}$. Durant l'exil dauphinois, il n'en essayait pas moins, lors de son unique incursion provençale en mai 1447, d'obtenir quelque soutien dans sa résistance à son père. Bien que soigneusement protocolaire, leur entrevue au château de Tarascon n'aboutit à rien ${ }^{62}$. Econduit par René, Louis s'investissait dans les pèlerinages provençaux avant de regagner le Dauphiné ${ }^{63}$. Les années 1440 auguraient de l'antagonisme qui serait toujours entre Louis XI et René d'Anjou. L'expédition milanaise prévue par Charles VII en 1453 et censée unir leurs forces, se démembrait au bout de quelques semaines ${ }^{64}$.

Les deux hommes auraient toujours des difficultés à coopérer ${ }^{65}$. Durant la guerre du Bien public René avait adopté une position flottante, négociant la paix avec les ligueurs pour Louis XI, mais ne faisant pas bloc avec lui ${ }^{66}$. Le roi n'était pas dupe, malgré la médaille allégorique (fig. 1) que René lui offrait pour le convaincre de sa loyauté ${ }^{67}$. Lui aussi se sentait profondément trahi par les princes angevins, et désormais leurs relations se feraient sous le sceau de la défiance.

En 1466, une nouvelle occasion de collaborer se présentait. René se voyait appelé au trône d'Aragon-Catalogne ${ }^{68}$, tandis que Louis XI ferraillait pour verrouiller le Roussillon et la Cerdagne récemment annexés ${ }^{69}$. Ils eurent pu faire cause commune et sur le papier il en était ainsi pour Louis, invoquant une fois de plus la parenté avec son «trés chier et trés amé oncle le roy de Secille ${ }^{70}$. Sur le terrain, la chose était moins évidente ${ }^{71}$. En mai 1472, un autre projet commun avortait. Il avait été

Seule l'enluminure de l'entrée de 1442 représente le dauphin en compagnie de son père (Calmette Joseph, «L'iconographie toulousaine de Louis XI », Annales du Midi, t.65, n²3, extrait, Toulouse, 1953, p.275-281).

${ }^{61}$ M. Kendall, p.44.

${ }^{62}$ A. Lecoy de la Marche, Le roi René, sa vie, son administration, ses travaux artistiques et littéraires, d'après les documents inédits des archives de France et d'Italie, Paris, 1875, t.I, p.254-255.

${ }^{63}$ Il n'aurait guère de relations avec René par la suite sinon par voie administrative, pour trouver un règlement aux désaccords frontaliers avec le comté de Provence, notamment au sujet de la souveraineté sur le petit comté de Gap (C. Roman d'Amat, Histoire de la ville de Gap, Gap, 1966, p.93-110). L'évêque et coseigneur de Gap Gaucher de Forcalquier refusait de prêter l'hommage au dauphin, protestant de son allégeance traditionnelle au comte de Provence. Des heurts apparaissaient dans le Gapençais dès 1444 et la question ne serait pas entièrement réglée avant l'union de la Provence à la France en 1481.

${ }^{64}$ B.n.F. ms. fr. 6966, fol. 369. Lecoy, op. cit., t.I, p.273-278.

${ }^{65}$ Lorsque Louis était couronné, René d'Anjou guerroyait au royaume de Naples contre Alphonse d'Aragon (Gaussin, op. cit., 1988, p.340-342). Par la suite, Louis XI écrivait aux divers protagonistes du conflit pour faire savoir combien il soutenait son oncle, au nom de la consanguinité (Lettres, t.II, p.10, 20 sept.1461 ; t.II, p.128-129, 30 mai 1463). Mais dans les faits, nulle armée française n'était dépêchée et le soutien claironné se limitait à des contributions financières. Pour avoir abandonné toute ambition sur les seigneuries de Gênes et Savone en 1463, prenant le contre-pied de Charles VII, Louis XI ne tenait plus à maintenir un royaume angevin à Naples. La tactique était perçue par les Angevins comme une trahison. De ce fait, le fils de René, Jean de Calabre, prenait une part active dans la guerre du «Bien public » en 1465 (Commynes, t.I, p.10-98).

${ }^{66}$ Lettres, t.II, p.255-257, 6 avril 1465 ; p.259-266, 10 avril 1465. Voir les doutes exprimés par Louis XI sur la conduite de son oncle dans Lettres, t.X, n 1977 , p.229, 6 mai 1465.

${ }^{67}$ F. Robin, La cour d'Anjou-Provence. La vie artistique sous le règne de René, Paris, 1985, p.258-263.

${ }^{68}$ Lecoy, op. cit., t.I, p.366-369.

${ }^{69}$ Basin, t.I, p.89-111.

${ }^{70}$ Lettres, t.III, p.116-118, 23 nov. 1466 ; t.X, nº1986, p.243-245, 29 oct. 1466 ; n 1987 , p.245-246, oct. 1466 ?

${ }^{71}$ Cependant, là encore, plusieurs dons du roi aux Angevins alimentaient la guerre catalane (Lecoy, op. cit., t.I, p.376; p. j., t.II, n71, p.340-341. Lettres, t.X, n¹989, p.247-249, 16 déc. 1466 ; n¹990, p.249-251). Quant aux armées royales, elles étaient bien sur place, mais avant tout pour servir la cause française et en donnant l'impression de vouloir gagner 
question depuis 1461 que le petit-fils de René, Nicolas, épouserait la fille aînée de Louis, Anne de France $^{72}$. Mais d'avoir envisagé d'autres partis pour sa fille selon les besoins de sa politique, Louis vit son futur gendre rompre cavalièrement les préparatifs pour aller demander la main à l'héritière du duc de Bourgogne, Marie ${ }^{73}$.

Comme on le voit, rien dans les faits ne concordait entre Louis XI et René d'Anjou. On n'en remarque pas moins dans les années 1468-1471, période de déclin de la puissance angevine et de forte attraction de la puissance bourguignonne, une profusion d'honneurs dont l'oncle faisait l'objet de la part de son neveu ${ }^{74}$. Autant de gestes honorifiques qui insistaient sur les liens du sang, tel le privilège royal de sceller à la cire jaune accordé en 1468 , pour René et ses descendants ${ }^{75}$. Pourtant l'hécatombe ne tardait pas à s'abattre sur les héritiers potentiels de René ${ }^{76}$, favorisant les intérêts de Louis en telle manière que des suspicions d'empoisonnement pèseraient sur lui ${ }^{77}$.

Nul n'ignorait plus en Europe la convoitise de Louis XI pour tous les domaines angevins. Apprenant que René préparait sa défense avec les voisins de la Provence, la duchesse de Savoie et le duc de Bourgogne, Louis XI le traduisait en mars 1476 devant le parlement de Paris pour crime de lèse-majesté et de haute trahison ${ }^{78}$. Puis il desserrait l'étau, ayant suffisamment épouvanté son vieil oncle, de si proche parenté ${ }^{79}$, pour tâcher d'obtenir une cession par la négociation ${ }^{80}$. L'oncle

du terrain sur la Catalogne. René et Jean en concevaient une fois de plus de l'amertume (Lettres, t.IV, p.169-170 et p.169 n.1, 13 déc. 1470).

${ }^{72}$ Lecoy, t.I, p.334-335. Papon, Histoire générale de Provence, Paris, 1784, t.III, p.394-395, une des sources consultées par Lecoy de la Marche, parle de 60.000 l.t. acquittées le 12 jan.1462.

${ }^{73}$ Lecoy, t.I, p.386-387. Un nouvel affront était fait à Louis XI, qui exigerait quelques années plus tard le remboursement intégral de la dot et des dons octroyés et probablement investis dans les deux guerres de la maison d'Anjou (Lettres, t.VIII, p.223-224, 25 juin 1480 : Louis XI ordonnait à sa Chambre des comptes de produire les archives concernant «tout ce que le feu duc Jehan de Calabre et son filz ont eu de nous »).

${ }^{74}$ Louis se faisait très présent dans le duché d'Anjou (Lettres, t.XI, Itinéraire, p.70-112) et leurs rencontres se multipliaient. René et Jeanne de Laval étaient reçus au château d'Amboise en octobre 1469, puis le duc invitait son neveu à une partie de chasse sur les bords de la Loire (Lecoy, t.I, p.374-375 :). Louis conférait à son oncle la place d'honneur auprès de lui lors des Etats généraux de Tours d'avril 1468, ainsi que la charge de lieutenant-général pour le Maine, l'Anjou et la Bretagne (Favier, p.306-307) ; pourtant dans les faits René ne participait plus depuis 1461 aux Conseils royaux (Gaussin, art. cit., 1985). L'année suivante, son neveu fondait l'ordre de Saint-Michel et René en était un chevalier précoce et décisionnaire (Lettres, t.IV, p.41-43, 26 oct. 1469). Lors du baptême du dauphin Charles en juin 1470, le duc d'Anjou figurait au premier rang, auprès du roi, sans pour autant être des parrains (Y. Labande-Mailfert, Charles VIII et son milieu (1470-1498). La jeunesse au pouvoir, Paris, 1975, p.14). Louis pouvait aussi faire appel à la caution morale que représentait son oncle pour garantir certains traités (Lecoy, t.I, p.373-374 et p.374, n.1 et 2 : le traité de Péronne en 1468 en est un exemple).

${ }^{75}$ Arnaud d'Agnel, Politique des rois de France en Provence, Paris, Marseille, 1914, t.II, Documents, $\mathrm{n}^{\circ} 1$, p.1-3. Lettres, t.III, p.348-349 et n.3, 10 juin 1469.

${ }^{76}$ En 1470, il perdait son fils Jean et son beau-fils Ferri de Lorraine, en 1471 son petit-fils naturel Jean, en 1473, son petit-fils Nicolas (A.d'Agnel, op. cit., 1914, t.I, p.7, 11. Lecoy, t.I, p.378-379).

${ }^{77}$ Lecoy, t.I, p.378, 389. Louis XI était également soupçonné d'avoir empoisonné son frère Charles en 1472 (Heers, p.138). En effet, les positions stratégiques du duché d'Anjou, au débouché de la Bretagne insoumise, des duchés de Bar et Lorraine, passerelle entre les territoires bourguignons et avant-mur contre l'Empire, trois duchés sous la main de René, intéressaient sérieusement le roi de France. En 1471, Louis faisait en sorte que le duc d'Anjou quittât définitivement ses duchés pour se retirer loin dans son comté de Provence souverain. Louis XI avait ainsi le champ libre. Dès 1472, il faisait ingérence en Anjou (Lettres, t.X, $n^{\circ} 2052$, p.327-328, 30 avril 1472. Lecoy, t.I, p.393). Sous couvert de protection contre les incursions bourguignonnes, il envoyait des troupes en Bar dès mars 1474 (Ibidem, t.V, p.217-218, 8 mars 1474). Il saisissait l'occasion du dernier testament de René en juillet 1474, document qui l'écartait officiellement de ses supposés droits, du chef de sa mère, sur les domaines angevins, pour faire un coup de force sur le Bar et l'Anjou (Lecoy, t.I, p.391-392). Touchant aux droits que Louis XI prétendait détenir sur la succession de René d'Anjou, je renvoie à la bonne étude du Marquis de Forbin, «L'union de la Provence à la France. 11 décembre 1481 », Mémoires de l'Académie de Vaucluse, $7^{\mathrm{e}}$ série, t.II, 1981, p.19-112.

${ }^{78}$ Forbin, op. cit., 1981, p.37 et n.62.

${ }^{79}$ Ibidem, op. cit., 1981, p.38 et n.64.

${ }^{80}$ Louis envoyait une première fois en avril 1476 ses ambassadeurs vers René à Pertuis en Provence (B.n.F. ms. fr. 10187, fol.18 $\mathrm{v}^{\circ}$ : instructions aux ambassadeurs datées du 24 avril 1475 selon la table du registre). Les discussions reprenaient directement quelques mois plus tard à Lyon (Commynes, t.I, p.355). René se maintenant dans la droite ligne de son testament, Louis XI pensait acheter son consentement implicite en lui promettant de fortes pensions. L'argent 
demeurant inflexible, Louis se rabattait sur son héritier : Charles II du Maine accordait à Louis XI le retour d'apanage de l'Anjou après la mort du vieux duc ${ }^{81}$. Celui-ci vivrait ses quatre dernière années dans la dépendance financière de son neveu ${ }^{82}$.

N'ayant plus à faire, après le 10 juillet $1480^{83}$, qu'avec sa mémoire, Louis XI la respectait. Le 2 août, il commandait un service funéraire à Notre-Dame de Paris «pour l'âme de feu [son] bon pere le roy de Secille, cui Dieu pardoint ${ }^{84}$. Le même jour il écrivait au receveur des aides de Paris au sujet du paiement dudit service afin qu'il fût « le plus solempnel que faire se pourra ${ }^{85}$. Autres lettres au chapitre d'Angers, au sein duquel René serait inhumé, pour que là aussi aux frais de Louis $\mathrm{XI}$ les obsèques fussent fastueuses « et ainsi que à estat de roy appartient ${ }^{86}$. La dépouille du vieux duc ne parvenait à sa sépulture dans Saint-Maurice d'Angers qu'une année plus tard. Ce qu'apprenant, le roi se manifesta auprès du chapitre angevin afin qu'ils fît «tout l'onneur à l'enterrement d'iceluy qu'il [lui] sera possible à faire et ainsi qu'il appartient » ${ }^{87}$. Louis XI se plaçait alors plus en héritier et successeur qu'en neveu. Devenu duc d'Anjou en vertu des accords de Châtellerault, administrateur du Bar en vertu d'un arrentement passé avec René juste avant sa mort, un manquement aux honneurs dus à son prédécesseur eût pu le faire passer pour un usurpateur $^{88}$.

La brillante munificence de René d'Anjou-Provence n'est plus à démontrer ${ }^{89}$. Si du point de vue des donations religieuses, Louis XI n'était pas en reste, les deux princes se sont très rarement associés devant Dieu. Dans les domaines héraldique et emblématique on note quelques exemples de leur coexistence. Dans un ancien manuscrit de Vendôme, on peut voir les armoiries de René jouxter celles du dauphin Louis. Les caractéristiques du blason de René donnent à penser que ce signe de concorde pourrait dater de 1453, année de l'expédition commune vers le Milanais ${ }^{90}$. Dans le duché de Bar leurs armes ont apparu conjointement sur un vitrail de la collégiale Saint-Pierre de Bar. Dans le chœur de l'église, au-dessus du maître-autel, se voyaient de bas en haut l'écu de Bar, ceux de René et de son fils Jean, puis les armes de France. À la pointe de la lancette, un Christ de pitié trônant sur un arc-en-ciel achevait cette pyramide des souverainetés. L'ouvrage était dû à la libéralité de René dans les années 1463-1464 et valait peut-être pour une proclamation d'alliance entre le duc de Bar, son fils administrateur, et leur suzerain français à la veille de la guerre du Bien public $^{91}$. Dans le même esprit semblent avoir été conçues les médailles commandées en 1463-1465 par René à F. Laurana et P. da Milano (fig.1 ${ }^{92}$. Mais ces productions se doivent à l'initiative de

était la nécessité première de René, dont une partie des revenus de l'Anjou et du Bar avaient été détournés par les hommes du roi.

${ }^{81}$ Accords de Châtellerault, passés avec Charles II du Maine pendant les conférences de Lyon (B.n.F. ms. fr.10187, fol.107, 6 mai 1476).

${ }^{82}$ Louis laissait son oncle user ses dernière forces en divers présents et protestations contre l'irrégularité ou les retards de paiement de ses pensions ; défaillances qui semblent parfois indépendantes de la volonté royale (Lettres, t.VIII, p.31-32, 17 juin 1479 ; t.VIII, p.34-35, 23 juin 1479). Mais ayant appris la mort imminente de René, Louis XI commandait d'ajourner les paiements (Ibidem, t.VIII, p.221-222, 24 juin 1480).

${ }^{83}$ Lecoy, t.I, p.426-427.

${ }^{84}$ Lettres, t.VIII, p.248-249, 2 août 1480.

${ }^{85}$ Ibidem, t.VIII, p.249-250, 2 août 1480.

${ }^{86}$ Ibid., t.VIII, p.252-253, 2 août 1480.

${ }^{87}$ Ibid., t.IX, p.67-68, 26 août 1481.

${ }^{88}$ Pour autant, à la mort du duc de Bourgogne dont il annexait aussi une partie des domaines, il agissait de façon contraire. En 1478, le Téméraire était officiellement poursuivi à titre posthume pour crime de lèse-majesté (Ordonnances, t.XVIII, p.396 et 402, 11 mai 1478).

${ }^{89}$ Robin, op. cit., 1985.

${ }^{90}$ C. de Mérindol, Le roi René et la seconde Maison d'Anjou. Emblématique, art, histoire, Paris, 1987, p.380. L'entente supposée autour de ce projet commun se limite en réalité à la période juin-septembre 1453 (P. de Thorey, t.I, p.405, n.1 ; Favier, 2001, p.146-147).

${ }_{91}$ Mérindol, op. cit., 1987, p.95-96, 174 et fig. 193.

${ }^{92}$ Le roi René en son temps (1382-1481), catalogue d'exposition du Musée Granet à Aix-en-Provence, Marseille, 1981, p.142-144. La médaille de la Pax Augusta est datée de 1463 (B.n.F., Cabinet des médailles, AV 150 bis). La médaille de Jean d'Anjou, de 1464, comporte sur son revers un temple de la justice surmonté de saint Michel terrassant le dragon. La présence du saint patron du royaume de France semble être une affirmation de loyauté (Mérindol, op. cit., 
René, qui ferait encore d'autres usages des signes français, notamment après son adhésion à l'ordre de Saint-Michel en octobre $1469^{93}$.

On relève un exemple avéré d'association de la dévotion des deux princes en comté de Provence. En souvenir de son pèlerinage à l'église Sainte-Marthe de Tarascon en 1447, le dauphin exilé en Brabant tenait à participer au financement d'un buste-reliquaire de la sainte de Béthanie offert par René ${ }^{94}$. L'année 1457, il s'engageait à compléter la somme de 3.000 écus d'or donnée par le comte de Provence pour la réalisation d'un buste en argent partiellement doré. La ville de Tarascon confiait le chantier à un orfèvre d'Arles, Etienne Dandelot. Le dauphin ne verrait jamais cette pièce d'orfèvrerie, confectionnée entre 1455 et 1458. Pourtant, insatisfait, il décidait d'en faire refaire la partie supérieure dès 1462 . Certainement plus à l'aise dans ses finances, le roi voulait accroitre la valeur du matériau du reliquaire et revenir ainsi sur le geste du comte de Provence pour offrir un buste en or. Pour ce, il investit 3.000 écus d'or, soit le montant exact de la somme que René avait consacré au précédent buste d'argent. Pour orner le buste d'argent déposé, Louis XI finançait l'adjonction de deux anges de même métal, par un don supplémentaire de 300 écus en mai 1463, au bénéfice de l'orfèvre tarasconnais Guillaume de Viridario ${ }^{95}$. Après le transfert des reliques, l'ancien buste était vendu au chapitre d'Avignon, métropole religieuse de l'église de Tarascon où le culte de Marthe était traditionnel ${ }^{96}$. Le socle d'argent était conservé, pour servir de piédestal au buste d'or.

Durant le règne, le nouveau reliquaire se verrait élargi puis le buste assis sur un socle d'or ${ }^{97}$; l'église se verrait gratifiée de cierges (1472), de lampes d'argent (1479), d'un jeu de calice et patène fleurdelisés, d'un tabernacle d'argent portant l'effigie du roi en priant (1480) $)^{98}$, d'un bras-reliquaire en argent et de diverses offrandes en numéraire $(1470,1481)$. René assistait en décembre 1470 au transfert des reliques de Marthe dans un buste reliquaire dont les parties les plus somptueuses ne lui devaient rien. En décembre 1478 était livré un buste entièrement en or massif d'un poids proche de $25 \mathrm{~kg}$ et bardé d'insignes royaux français (fig.2). Pour sa part, le comte de Provence ne participait que très modestement à l'embellissement de cette église pourtant dédiée à l'une des patronnes de la maison d'Anjou. Il laissait ses armes sur une cloche datée de $1469^{99}$ et faisait une offrande en $1478^{100}$. À quelque pas d'un des plus puissants châteaux de Provence, dans une église d'un pays souverain où les comtes angevins avaient traditionnellement pourvu aux besoins du culte, c'était le roi de France qui imposait son patronage. Cet exemple illustre un type de confrontation très particulier qui semble avoir existé entre René d'Anjou-Provence et Louis XI.

Louis XI faisait connaître sa générosité partout mais pas au hasard. Dans de nombreux cas sa piété a fait bon ménage avec la stratégie politique. Les sanctuaires des domaines angevins apparaissent comme des lieux privilégiés du patronage royal. Bien avant de devenir duc d'Anjou, les prodigalités de Louis visaient de nombreux sanctuaires du duché tels Notre-Dame de Béhuard, le Puy-Notre-Dame ${ }^{101}$ ou Notre-Dame-de-Nantilly à Saumur ${ }^{102}$, dont les églises se constellaient

p.175 et fig. 282-283; cab. médailles, princes français $\mathrm{n}^{\circ} 301$ et AV 148). Celle de la Concordia Augusta, fut probablement réalisée pour être offerte à Louis XI ; elle est datée vers 1465 (AV 143 et 144).

${ }_{93}$ Mérindol, op. cit., p.149, n.8. L'écu de René pouvait être accompagné du collier à lacs et coquilles de l'ordre.

${ }^{94}$ Lapeyre, op. cit., 1986, p.99 et n.3-8, complété par C. Roux, Tarascon au XVe siècle, Espace et société au temps des derniers comtes angevins de Provence (1400-1481), thèse soutenue à l'université d'Aix-Marseille I en 2004, en cours de publication, p.610-613.

${ }^{95}$ C. Roux, thèse citée, p.611 et n.22, 30 mai 1463.

${ }^{96}$ Marthe était en effet considérée comme «l'apôtre d'Avignon » (Faillon, t.I p.592-595 ; p.1237-1240, 1254) et il existe un autre exemple de cession de mobilier cultuel de Tarascon à Avignon : le maître-autel d'argent de sainte Marthe offert à l'église de Tarascon vers 1373 par le pape Grégoire XI (t.I, p.1235).

${ }^{97}$ Lapeyre, op. cit., 1986, p.98-112 pour toutes les informations sur les dons de Louis XI à Sainte-Marthe de Tarascon. Le chantier du buste-reliquaire s'est étalé de novembre 1462 à décembre 1478.

${ }^{98}$ Ibidem, p.111 et n.7 pense que ces œuvres, ainsi que la main-reliquaire, furent dérobées en 1550 et jamais localisées depuis.

99 Y. Esquieu, «L'église Sainte-Marthe de Tarascon », Congrès archéologique de France, 1976, p.128 et n.11. A-t-il participé au financement de cette cloche?

${ }^{100}$ Mérindol, op. cit., p.208; Robin, op. cit., p.54-55 et n.267, 29 septembre 1478.

${ }^{101}$ C.-Brouquet, p.185-190. 
d'emblèmes royaux français. En comté de Provence, l'ensemble abbatial de Saint-Maximin - la Sainte-Baume pouvait s'enorgueillir d'attirer bien des dons. Fondé par l'angevin Charles II, régulièrement doté par les comtes de Provence et les rois de France, les deux princes trouvaient légitimité à s'y montrer généreux. Dévot de Marie-Madeleine, René se montrait toujours préoccupé par l'état de nécessité qui touchait les deux sanctuaires. Mais ses diverses mésaventures militaires et l'étranglement de ses revenus à partir de 1474, ne lui permettaient guère de les relever véritablement. Son attachement se manifestait principalement par d'assidus pèlerinages ${ }^{103}$, l'octroi d'exemptions fiscales, de nombreuses sollicitations au pape afin qu'il confirmât d'anciens privilèges ${ }^{104}$ ou qu'il émît des bulles d'indulgence susceptible d'attirer les dons ${ }^{105}$, que le comte ne faisait pas en suffisance ${ }^{106}$.

C'est le dauphin de France, lors de son pèlerinage de mai 1447, qui fournit aux dominicains une chapelle dans la grotte de la Sainte-Baume afin de protéger leurs prières des eaux d'infiltration (fig.3). Les trois murs extérieurs en étaient blasonnés des armes de France écartelées du Dauphiné $^{107}$. Quelques semaines après, en juin 1447, René offrait à Saint-Maximin 120 livres de rente pour une messe ainsi que 100 florins à employer par le prieur aux «réparacions de l'eglise ${ }^{108}$. En 1448 il manifestait son autorité temporelle en autorisant l'ouverture du reliquaire de Madeleine et réaffirmant que le sanctuaire était de fondation angevine et qu'il en était lui-même le patron, protecteur et défenseur ${ }^{109}$. Mais à la Sainte-Baume, c'était le dauphin de France une fois de plus qui faisait compléter, en juillet 1456, le maître-autel de la grotte par un retable sculpté de sept statues d'albâtre dont son effigie en priant. On avait engagé le sculpteur Jean de Fontay au prix de 104 florins $^{110}$. Tous les pèlerins pouvaient se rendre compte que c'était un prince de France, et non le comte souverain, qui avait pourvu aux difficultés matérielles du prieuré perché. En 1458, René patronnait le retour de la mandibule inférieure de Madeleine d'Aix à Saint-Maximin et obtenait une bulle du pape au sujet de la cession des biens d'un couvent voisin ${ }^{111}$. Dans cette même décennie 1450 il délivrait à la basilique un ex-voto en cire comportant ses armoiries et celles de son épouse Jeanne $^{112}$. Le roi de France, quant à lui, faisait abonder les libéralités sur les deux sanctuaires magdaléniens. En avril 1462, il écrivait au duc de Savoie afin de hâter ses aumônes envers la basilique. En effet, les dominicains s'étaient adressés à lui plutôt qu'à leur protecteur et souverain, pour le recouvrement d'une fondation ${ }^{113}$. En août 1472, Louis prévoyait d'offrir un ex-voto en forme d'une ville d'argent au sanctuaire de la vallée ${ }^{114}$. En février 1476, il confirmait une rente, accordée précédemment, de 1200 l.t. annuelles et perpétuelles, dont plus de la moitié irait à la

\footnotetext{
102 A. Mussat, « Notre-Dame-de-Nantilly à Saumur », dans Congrès archéologique de France, CXXIIe session, 1964, Anjou, Paris, 1964, p.560 et 570-571.

${ }^{103}$ Naturellement, ces visites donnaient lieu à des aumônes comme en mars 1478 (Robin, op. cit., 1985, p.54 et n.266).

${ }^{104}$ Faillon, t.I, p.1007-1009.

105 Ibidem, t.I, p.994-998 : René obtenait une première bulle d'indulgence du pape le 22 juillet 1435 (voir p.j., t.II, n²16, p.1171-1174); peu efficace, elle devait être renouvelée le 13 août. Par lettres du 16 mars 1437 il octroyait une modeste rente. Le 22 mars 1438 René fondait une messe haute (p.j. n²03, p.1127-1132). Troisième bulle d'indulgence obtenue du pape en 1442 (p.j. n²17, p.1175-1180) ; une quatrième en 1473 (Mérindol, op. cit., 1987, p.202).

${ }^{106}$ Voir une liste des nombreux dons faits aux deux sanctuaires dans Mérindol, op. cit., 1987, p.201-204.

${ }^{107}$ Faillon, t.I, p.1000.

${ }^{108}$ Lecoy, t.II, p.55. Robin, op. cit., 1985, p.54 et n.264.

${ }^{109}$ Faillon, t.I, 1005 ; p. j. t.II, n²25, 226, 227.

${ }^{110}$ H. Requin, «Jean de Fontay et le tombeau d'Alain Chartier. Mémoire lu au Congrès des Sociétés savantes par M. l'abbé Requin, correspondant du Comité à Avignon », dans Bulletin archéologique, bull. du comité des travaux historiques et scientifiques, 1892, p.434-443.

${ }^{111}$ Faillon, t.I, p.1007-1009 : bulle du 16 novembre 1458. O. Pächt, dans « Dévotion du roi René pour sainte MarieMadeleine et le sanctuaire de Saint-Maximin », Chronique méridionale. Arts du Moyen Age et de la Renaissance, Centre international de documentation et de recherche du Petit Palais d'Avignon, ${ }^{\circ} 1,1981, \mathrm{p} .15-28$, émet l'hypothèse que René aurait dès 1448 fait compléter le buste-reliquaire de Madeleine à Saint-Maximin. Il aurait commandé la réalisation du masque d'or couvrant la face du crâne de la sainte.

${ }_{112}$ Mérindol, op. cit., 1987, p.202, 1455-1459. Plus tard, on a pu voir ces mêmes armoiries sur des vitraux de l'église.

${ }^{113}$ Lettres, t.II, p.44-45, 15 avril 1462.

${ }^{114}$ Lapeyre, op. cit., 1986, p.87 : il pourrait s'agir de la ville bretonne de La Guerche, conquise par le roi. Gaussin, 1988, p.431 évoque également une châsse d'argent que Louis aurait offerte à la Sainte-Baume.
} 
reconstruction de l'une des églises et le reste à la fondation d'une messe solennelle hebdomadaire ${ }^{115}$.

Faisant du comté sa dernière résidence (déc. 1471-juil. 1480), René accentuait ses contributions au double sanctuaire magdalénien. Il faisait dresser, lors d'un passage à la basilique en janvier 1473, un triple acte officiel de donation de quatre lampes à huiles ${ }^{116}$. En octobre 1476, il se préoccupait du reliquaire des cheveux de la Madeleine à Saint-Maximin, en faisant dorer l'ange qui le supportait ${ }^{117}$. Jusqu'alors les dons directs de René avaient été sans commune mesure avec ceux de Louis. Mais en décembre 1476, après avoir obtenu théoriquement la rétrocession de ses droits sur l'Anjou ${ }^{118}$, il accroissait l'effectif du collège de Saint-Maximin de 25 frères et 3 docteurs, respectant ainsi les volontés de son prédécesseur Charles II d'Anjou. Il fixait pour cela un revenu annuel de 3.000 florins et faisait reconnaître sa fondation par le pape Sixte IV en mai 1477. En prévision de nouveaux bâtiments à construire pour abriter ce collège abondé ${ }^{119}$, le comte proposait d'unir quelques prieurés locaux à la mense des religieux. Sixte IV consentit, moyennant quelques réserves, par bulles de juillet 1477. Mais devant l'insuffisance des revenus ainsi engendrés, René suscitait pour la cinquième fois des lettres d'indulgence, rédigées en août $1477^{120}$. De 1477 à 1480 , il donnait divers ornements : en juillet 1477 un crucifix de bois à la Madeleine «de la hauteur d'un homme » à 115 florins pour orner le chœur de l'église Saint-Maximin, en août 1477 un « ouvraige » de six écus destiné à la Sainte-Baume ${ }^{121}$, la même année une «croix-reliquaire en or qui [...] contient le morceau de la vraie croix rapporté de Palestine »par Marie-Madeleine et ses accolytes $^{122}$, en 1478 le reliquaire dit de la Sainte-Ampoule portant ses armoiries, sans précision de date $^{123}$. On note encore la même année des dons faits aux reliques de Saint-Maximin ${ }^{124}$.

Par voie testamentaire, René se montrait bien plus généreux. Ses testaments de 1453, 1471 et 1474 prévoyaient un legs de 6.600 florins ou 4.400 1.t. pour l'achèvement de la basilique, lequel était toujours en suspens ${ }^{125}$. Mais les legs n'engagent que les finances des héritiers. Louis XI règlerait lui-même cette libéralité, puisqu'en décembre 1481 il était devenu le successeur de René en comté de Provence. Il lui revenait dès février 1482 de confirmer tous les privilèges du sanctuaire $^{126}$. En avril 1482, le gouverneur Palamède Forbin avait obtenu son aval pour le versement d'une rente annuelle de 1.000 florins jusqu'à concurrence des 10.400 1.t. constituées par l'addition des libéralités testamentaires de René et de Charles III. L'argent serait prélevé sur la recette de Provence ${ }^{127}$. Mais Louis XI ne tarderait pas à confirmer la poursuite de ses excellentes intentions à l'égard du sanctuaire. En janvier 1483, ses lettres patentes gratifiaient "l'église de

\footnotetext{
${ }^{115}$ Faillon, t.I, p.1001-1002 et t.II, n²46, p.1317-1318, 18 fév. 1475 (a.st.). L’offrande est commémorée en 1561 : cf t.I, p.1022 et t.II, $\mathrm{n}^{\circ} 284$, p.1429-1432.

${ }^{116}$ Faillon, t.I, p.1010. Deux lampes devraient briller jour et nuit devant le maitre-autel et deux autres devant le tombeau de Madeleine, et le montant nécessaire à deux mesures d'huile serait prélevé annuellement sur ses droits.

${ }^{117}$ Lecoy, t.II, p.j., n ${ }^{\circ} 88$, p.376 donne pour cela un versement de 18 florins 2 gros le 10 oct. 1476 . Sur le reliquaire des cheveux de Madeleine se reporter notamment à Faillon, t.I, p.910, 1126.

${ }^{118}$ Ibidem, t.II, p.364-365. 16 sept. 1476.

${ }^{119}$ Peut-être à mettre en rapport avec ce don sans date de 200 florins pour réparer le dortoir de la Sainte-Baume évoqué par Faillon, t.I, p.1008.

${ }^{120}$ Ibidem, t.I, p.1013-1018 ; t.II, p.j. n²06-209 et n²21, 222, 224. Seul le prieuré de Château-Royal fut uni au couvent de Saint-Maximin. Le 16 janvier 1477, René ordonna l'exécution de cette bulle. L'héritier de René, Charles III de Provence, confirmait la fondation du collège par son oncle dès le 2 sept. 1480

${ }^{121}$ Robin, op. cit., 1985, p.76 et n.226, 227, p.229 et n.6, 7, 8 .

${ }^{122}$ C. Desvignes-Mallet, «Sainte Marie Madeleine et la Provence au Moyen Age et au début du XVIe siècle », La prédication de Marie Madeleine, cat. d'expo., Musée du Vieux Marseille, Aubagne, 2006, p.75.

${ }_{123}$ Desvignes-Mallet, art. cit., p.56.

${ }^{124}$ Mérindol, op. cit., 1987, p.204.

${ }^{125}$ Faillon, t.I, p.1018 ; p.j. t.II, n²19, p.1181 : la somme léguée revenait à une pension de 560 florins par an sur 10 ans. Lecoy, t.I, p.276 et n.1, t.II, p.55 et n.2. Les divers dons de René n'ont jamais permis de son vivant la construction des dernières travées de l'église de Saint-Maximin. L'ouvrage fut réalisé dans les trois premières décennies du XVIe siècle (B. Montagnes, «La basilique de la Madeleine à Saint-Maximin », Congrès archéologique de France, Le Pays d'Aix, Paris, 1988, p.238-253).

${ }^{126}$ Faillon, t.I, p.1022; t.II, n²45, p.1315-1318

${ }^{127}$ Ibidem, t.I, p.1021 et t.II, n²43, p.1305-1310, 7 avril 1482. 6.000 1.t. avaient été léguées par Charles III.
}

Frizet Yannick

Page 12

$09 / 06 / 2019$ 
Saint-Maximin, où gist et repose le précieux chief de ladicte dame » d'une pension supplémentaire et perpétuelle de près de 4330 1.t. en exécution d'un vœu ${ }^{128}$. À y regarder de près, le montant annuellement alloué par le roi de France correspond à l'ultime don du comte René (4.400 1.t.).

Voilà qui achève de donner le sentiment d'une concurrence devant les libéralités respectives de René d'Anjou et de Louis XI au sanctuaire de Saint-Maximin - la Sainte-Baume. Quand le premier ne parvient pas, ni par la multiplication des petites offrandes, ni par ses multiples interventions auprès du pape, à relever et agrandir efficacement les deux sanctuaires nécessiteux, le second sait apporter de solides aménagements et pensions. Jamais leurs offrandes ne s'associent, elles alternent dans le temps et donnent à penser à une rivalité de la générosité. En effet, les églises de Saint-Maximin et de la Sainte-Baume donnaient à voir les armoiries du roi de France, à entendre son nom, au moins autant que ceux du souverain comte René. Quant à Sainte-Marthe de Tarascon, le patronage de Louis XI semble y avoir été bien supérieur. Gageons que ces trois centres religieux, gâtés à la mesure de leur influence et de leur prestige, se montrèrent peu enclin à s'opposer à la future union de la Provence à la couronne.

\section{Un compagnon de prière pour Charlotte de Savoie}

A l'encontre de la volonté royale, le dauphin Louis célébrait le 8 mars 1451 un mariage par procuration avec Charlotte de Savoie, une fillette de douze ans ${ }^{129}$. Par ce moyen il se procurait un allié contre son père et d'importantes recettes sous la forme d'une dot, alimentée par les villes du Piémont et du comté de Nice ${ }^{130}$. Suite à l'entrée du couple delphinal à Grenoble le 2 avril 1451, des villes du Dauphiné leur octroyaient un don de joyeux avènement de la dauphine ${ }^{131}$. Il aurait grand mal à rassembler le montant de la dot promis par le duc de Savoie ${ }^{132}$ malgré l'intercession de Charlotte affirmant à son père que son mari faisait d'elle « la plus heureuse femme qui oncques fut ${ }^{133}$. Depuis l'exil bourguignon, Louis alimenterait encore les comptes de sa jeune épouse ${ }^{134}$. Elle vint le retrouver en Brabant en 1458 pour consommer le mariage. Le 27 juillet 1459, un premier fils nommé Joachim voyait le jour. Dans l'instant, Louis écrivait au moins quatre lettres pour annoncer fièrement : «au matin nostre trés chiere et trés amée compaigne s'est acouchée et delivrée d'un beau filz ${ }^{135}$. L'espoir d'un héritier périt assez vite puisque Joachim ne vécut que quelques mois ${ }^{136}$. En mai 1460, une fille vint au jour, Louise, qui ne survécut que quelques heures.

En mars 1461 Charlotte était à nouveau enceinte et Louis demandait à son père la venue de deux parisiennes pour prendre soin de la parturiente ${ }^{137}$. Le dernier enfant de l'exil serait une fille,

\footnotetext{
${ }^{128}$ Ibid., t.I, p.1022-1024 ; t.II, n²49, p.1323-1326. Voir P. de Thorey, op.cit., t.II, p.333, n ${ }^{\circ} 1819$. Ce vœu initial était-il celui de l'annexion du comté de Provence ? Quoi qu'il en soit, il trouva son exécution peu après cet accroissement du domaine royal.

${ }^{129}$ Voir le traité de mariage dans P. de Thorey, t.I, n850, p.321-323, 14 fév. 1451 ; n.1, p.321-322.

${ }^{130}$ Lettres, t.I, n ${ }^{\circ} 79$, p.282-322, 1459-1461.

${ }^{131}$ P. de Thorey, t.I, n.1, p.321-322 et n॰885, p.337, 13 juil. 1451.

${ }^{132}$ Lettres choisies, $\mathrm{n}^{\circ} 30$, p.71-72 : en août 1457, il réclamait encore une partie de son dû.

${ }^{133}$ Lettres choisies, $\mathrm{n}^{\circ} 31$, p.72, août 1457 . Louis pourvoirait toujours correctement aux besoins de la dauphine et de son hôtel. Cf Heers, p.91 ; P. de Thorey, t.II, n¹910, p.394 : 17 juil. 1455 ; t.II, n¹913, p.395-396 : 26 fév. 1456. Mais Louis ne montrait aucun empressement à la rappeler auprès de lui et elle ne vint résider définitivement en Dauphiné que peu après sa fuite vers le duché de Bourgogne. En septembre 1456, il se préoccupait à distance de faire aménager son logis à Grenoble pour l'installation de sa «femme »(P. de Thorey, t.I, n.4, p.506-507, 14 sept. 1456). Les travaux étaient en cours dès le 20 déc. 1455 (t.II, n¹911, p.395). En octobre 1456, on lui annonçait depuis le Dauphiné que « Madame est ycy » (Lettres, t.I, n71, p.265-266, 22 oct. 1456).

${ }^{134}$ Lettres, t.X, n 1925 , p.158-159 : de Besançon, le 10 sept. 1456, Etienne Achart était prié de délivrer à l'argentier de la dauphine la somme de 2.000 1.t. en ces termes : «Et en ce ne fectes faulte, affin (sic) que ladicte despence soit entretenue sans aulcune rompture ».

${ }^{135}$ Ibid., t.I, n 79 , p.105, 27 juillet 1459, à son frère le duc de Berry. Voir aussi, t.I, n 78, p.104-105, au roi de France ; $\mathrm{n}^{\circ} 80$, p.106-107, à l'évêque de Paris ; n81, p.107-109, à la ville de Paris.

${ }_{136}$ Heers, p.48 fait naître Joachim le 15 juil. 1459 , ce que les quatre lettres citées contredisent.

${ }^{137}$ Favier, p. 180 : la chose était acceptée en Conseil royal le 22 mars 1461.
} 
nommée Anne. Elle se fortifiait au moment où son père et sa mère étaient conjointement sacrés roi et reine de France en août $1461^{138}$. Louis XI poursuivrait envers la reine les usages de respect et de prodigalité initiés durant le delphinat ${ }^{139}$. Plusieurs exemples de son attention à l'égard des réceptions de la reine dans les villes du domaine et d'ailleurs apparaissent dans les sources ${ }^{140}$. Si le nouveau roi entretenait convenablement la dignité de son épouse, il ne semble pas avoir souhaité sa collaboration au gouvernement du royaume. Il attendait d'elle un héritier mais c'est à une troisième fille, nommée Jeanne, qui vivrait boiteuse et bossue, qu'elle donna le jour en 1464. Deux ans plus tard, c'était un fils qui venait couronner leurs unions, mais le petit François ne vécut que quelques heures en décembre $1466^{141}$.

Symboliquement, Charlotte reçut le collier de l'ordre de Saint-Michel ${ }^{142}$, mais concrètement elle n'apparait jamais parmi les membres du Conseil royal ${ }^{143}$. Il se produisait cependant que le roi employât la reine pour les besoins de sa diplomatie ${ }^{144}$. En 1478 Louis XI recourait aux services de Charlotte pour connaître la vérité d'un mariage qui avait été conçu entre la fille de la duchesse de Savoie Anne et le prince de Tarente, Federigo ${ }^{145}$. Charlotte paraît avoir aspiré à plus de responsabilités que ce que le roi lui confiait. Les chroniqueurs rapportent qu'elle s'investissait beaucoup dans la réconciliation du roi avec son frère Charles, laquelle aboutissait en 1469. On la sait aussi frustrée d'avoir été écartée par son époux de la régence de Charles VIII, au profit de leur fille, future Anne de Beaujeu ${ }^{146}$. Pourtant c'était Charlotte qui avait dirigé le fastueux accueil de la future dauphine de France Marguerite à Amboise, le 22 juin $1483^{147}$.

\footnotetext{
${ }^{138}$ Ibidem, p.192-193. Anne deviendrait une des rares personnes dont il se sentirait véritablement proche (J. d'Orliac, Anne de Beaujeu, roi de France, Paris, 1926, p.9, 37 et passim).

${ }^{139}$ Dès septembre 1461, et plusieurs fois par la suite, il protégerait la condition et les privilèges des gens de son hôtel (P. de Thorey, t.II, n 1326 , p.27 et n.2 ; le 8 décembre 1461, il donnait des seigneuries dauphinoises à Louis Richard, pour son mariage arrangé par le roi avec une dame d'honneur de la reine. Voir l'obligeance du roi pour Jean de Lessau, « secretaire de nostre trés chiere et trés amée compaigne la royne », dans Lettres, t.VI, n918, p.64-65, 11 juin 1476 et $\mathrm{n}^{\circ} 955$, p.121-122, 31 jan. 1477. Dans cette dernière il justifiait sa générosité : «pour ce que nous nous voulons servir dudit de Lessau »). En 1464, il priait un «bon compère » anonyme de dénouer une affaire qui réjouirait la reine (Ibidem, t. II, $\mathrm{n}^{\circ} 136$, p.220-221, à « son bon compère ? », fin 1464 : « Je vous pry que vous veillez tenir la main....., et ma femme vous en dira grant merciz »). La même année Louis réglait le protocole des repas à la cour, prescrivant la présence de la reine et de leurs enfants (Gaussin, op. cit., p.408).

${ }^{140}$ Le 29 novembre 1462, il remerciait les magistrats de Metz du bon accueil jadis réservé «à nous comme aussy à nostre trés cher[e] et trés amée compagnie (sic) la royne et aux siens » (Lettres, t. X, supp., n¹946, p.184-185, aux échevins et jurés de Metz).

${ }^{141}$ Favier, p.57.

142 Ibidem, p. 239.

${ }^{143}$ Gaussin, art. cit., 1985. L'on connaît la méfiance qu'il portait aux femmes en général et en particulier au sein de l'Etat (Favier, p.210-211). Il tenait fermement au principe de la loi salique, sans l'observation duquel il n'aurait jamais acquis la couronne (Lettres, t.VIII, p.275-277, 9 oct. 1480, aux seigneurs du Bouchage et de Soliers : «que les filles herident (sic), qui est contre raison, et là où il a si grant peril que de perdre la couronne »; « nous avon beaucop plus à faire, ce nous consention que les filles heritassent, car je perdroye la couronne ». En juin 1462, la reine d'Angleterre Marguerite d'Anjou s'en venait en France pour solliciter le soutien du roi. A travers deux lettres, on voit Louis XI tout mettre en œuvre pour qu'elle ne rencontre pas Charlotte. Il écrivait tout d'abord à Aymar de Poisieu en ces termes : «nous avons sceu que la royne [Marguerite] vient à Tours, [...] aussi que ma femme n'aille point devers elle à Tours, pour rien qui soit. » Plus loin, Louis parait à une autre éventualité : «Et si d'adventure la royne venoit à Amboyse, [...] amenez ma femme à Melun » (Lettres, t.II, n³5, p.54-56, juin 1462). Suite à quoi il rédigeait une missive à Charlotte, lui enjoignant avec douceur de venir le rejoindre à Melun (Lettres, t. II, n³6, p.56-57, juin 1462: «Ma femme, je ne m'en puis si tost aller que je pensoye, pour plusieurs grans affaires que me sont survenues, et pour ce ... venez vous en à Melun »).

${ }^{144}$ La reine était ainsi envoyée au devant de Léon de Rosmital, prince de Bohême, qui traversait le royaume pour gagner la Terre Sainte. En l'absence du roi, l'hôte était ainsi joyeusement accueilli à Meung-sur-Loire par Charlotte et ses dames d'honneur, qui donnèrent pour lui un festin et facilitèrent sa route vers le sud (Gandilhon, p.35 et n.2).

${ }^{145}$ Lettres, t.VII, p.159-163, 8 sept. 1478, à Philippe de Commynes : «Quando io vidi queste cose io commissi alla Reina che sapessi da detta mia nipote, se gli era cosi qual cosa ». La petite Anne était la nièce du roi, mais aussi la nièce de Charlotte, qui appartenait à la maison de Savoie et qui serait peut-être plus à même d'obtenir de bonnes informations. ${ }^{146}$ Commynes, t.II, p.83, n.3.

${ }^{147}$ C.-Brouquet, p.109.
} 
Pour établir Charlotte, Anne et les futurs enfants de France dans une résidence à la fois proche de lui, sûre et confortable, Louis XI entreprenait à partir de 1463 des travaux au château d'Amboise $^{148}$. À partir de 1470 , elle en faisait sa résidence principale ${ }^{149}$. Louis XI, roi fondamentalement gyrovague ${ }^{150}$, l'y rejoignait régulièrement jusqu'en $1473^{151}$. Le 30 juin 1470 , à Amboise, Charlotte donnait le jour à un fils : Charles. Face à un nourrisson de santé précaire, le roi se montrait réservé et se réjouissait davantage de la naissance de François, deuxième du nom, en octobre 1472. Malheureusement, le septième et dernier enfant du couple, qui avait suscité tous les espoirs, décédait au bout d'une dizaine de mois, tandis que Charles grandissait. En ce funeste mois de septembre 1473, Louis XI faisait le vœu de n'avoir plus aucune relation adultérine ${ }^{152}$. Commynes semble confirmer l'exécution de ce vœu : «Des dames il ne s'en est point meslé du temps que j'aye esté avecques luy »(1468-1483) ${ }^{153}$. Seul mâle restant, Charles mobilisait toute l'attention de sa mère ${ }^{154}$; ce qui n'empêchait pas le roi de lui confier l'éducation d'autres enfants, qui lui tenait à cœur, à savoir les petites-filles naturelles de son père, Marguerite et Gillette de Coëtivy (1477) $)^{155}$, leur cousine Renée de Bueil qui était «grosse » $(1480)^{156}$, et Anne de Savoie qu'il acceptait à présent d'unir à Federigo d'Aragon (1480) ${ }^{157}$. Il arrivait que Louis éloignât la reine du royal nid, mais ce fut pour préserver sa santé d'une épidémie de rougeole ${ }^{158}$. On ne peut qu'insister sur la grande confiance que, selon ses lettres, Louis XI témoignait à son épouse en regard de ses capacités maternelles ${ }^{159}$. Mais avec la maladie et la diminution physique, le comportement de Louis XI s'infléchissait vers une méfiance outrancière qui touchait même les plus proches. En juin 1483, il renvoyait la reine Charlotte elle-même. Il voulut qu'elle s'éloignât de lui,

\footnotetext{
${ }^{148}$ En mai, il gourmandait son trésorier Bourré à cause des difficultés rencontrées pour le paiement d'un artisan ayant travaillé à Amboise, apparemment selon le bon plaisir de la reine (Lettres, t.II, $\mathrm{n}^{\circ} 77$, p.125-127, 25 mai 1463 : « nous voulons que en toute diligence lesdictes euvres se continuent et parachevent le plus tost que possible sera. »). Les aménagements ne seraient pas achevés avant 1478, mais comme certaines lettres sus-citées de juin 1462 et mai 1463 le laissent à penser, Charlotte séjournait à Amboise durant les travaux du château.

${ }^{149}$ C.-Brouquet, p.92-94.

${ }^{150}$ Gandilhon, p.1-2.
}

${ }^{151}$ Voir Lettres, t.XI, Itinéraire, p.3-236. A Amboise la reine était à même de s'adonner à une activité pour laquelle son époux l'encourageait, à savoir l'éducation des enfants. Quelques livres de sa bibliothèque pouvaient l'aider dans sa tâche, tels Le livre du gouvernement des rois et des princes, Le Livre de l'Instruction d'un jeune prince ou encore Le traité d'éducation pour ses filles, du chevalier de la Tour Landry. La liste des livres de la succession de Charlotte de Savoie est reproduite dans C.-Brouquet, p.126-130.

${ }^{152}$ Sur les maîtresses de Louis XI voir Favier, p.55-57. En 1466, il légitimait sa fille naturelle avec Felice Regnart ou Reynaud (Ordonnances, t.XVI, p.461, 25 fév. 1466 (n.st.). Sur F. Regnart voir aussi P. de Thorey, t.I, n943, p.360-362 et n.3. Sur sa fille naturelle avec Marie de Sassenage et le soin qu’il en a pris, voir Lettres, t.IV, n³41, p.6-7, 5 juil. 1469.

${ }^{153}$ Commynes, t.II, p.82, n.2; p.83 et n.1.

${ }^{154}$ Labande-Mailfert, p.17. Favier, p.240.

${ }^{155}$ Lettres, t.VI, n 1025 , p.226-227, et p.226, n.3, 7 sept. 1477 : il exhorte leur père à les confier à la reine : « vous ay jà escript que les envoissiez avecques la royne. Je ne sçay si vous l'avez fait, et pour ce je vous prie que vous les lui envoyez incontinent; et elles seront bien traictées, ainsi que je l'ai escript à la royne ».

${ }^{156}$ Lettres choisies, n 487 , p.451-452 et p.451, n.3, 30 nov. $1480:$ : Monseigneur du Plessis, je vous envoie ma nièce la sénéchale d'Anjou laquelle est grosse, ainsi que m’ont dit les médecins. Et, pour ce, qu'elle soit bien traitée et logée près de la reine, et qu'il n'y ait faute. »

${ }^{157}$ Ibidem, n485, p.450-451, 24 mars 1480, au sire du Bouchage : «Et, pour ce que la reine s'en est allée à Montrichard, je vous prie que lui meniez ma nièce [Anne de Savoie], laquelle la fera coucher avec elle, ou en sa chambre. Dites à la reine qu'elle se rende ici le mercredi d'après Pâques, et qu'elle la mène avec elle ».

${ }^{158}$ Aucun ton «tyrannique » ne transparaît dans ses lettres de 1472 ou 1473 où le roi aménageait ses ordres : «et quant elle vouldra venir veoir ses enffans, elle y pourra venir » (Lettres, t.X, n²047, p.323, 2 mars 1472 (?), à Mme de Montsoreau). Louis prévoyait que la reine se retirerait à Montrichard, à moins de vingt kilomètres d'Amboise. Apparemment, la rougeole sévissait au château d'Amboise parmi les enfants royaux. Le souci d'en préserver son épouse n'en est que plus notable. Ce type d'attention est propre à nuancer l'image calamiteuse donnée de Louis XI par Basin, t.I et II, passim.

${ }^{159}$ On ne peut non plus aller contre les nombreux témoignages de considération et même d'affection dont le roi usait envers son épouse (Lettres, t.VII, p.157-159, 8 sept. 1478 : à François de Genas, trésorier général du Languedoc il ordonnait de régler la pension de René d'Anjou, « sans toucher au fait de mes gardes et despenses de moy, de la reyne, de monseigneur le daulphin, ni des officiers de mon hostel »). 
non sans pourvoir à son rang, comme on peut le lire dans cette missive à son trésorier général du Languedoc : «Monseigneur le général, la reine s'en va par delà. Je vous en avertis afin que pourvoyiez à tout. ${ }^{160}$. Charlotte s'éteignait trois mois après Louis XI, le $1^{\text {er }}$ décembre 1483 . Elle fut inhumée auprès de son époux à Notre-Dame de Cléry ${ }^{161}$.

La compagne du roi était surtout celle sur qui reposait la pérennité de la dynastie. L'idée, particulièrement fondée au vu de la mortalité qui touchait les enfants royaux, de ne laisser derrière lui aucun héritier mâle, faisait redoubler Louis XI de ferveur religieuse. Un grand nombre de ses prières étaient tournées vers des saints susceptibles d'intercéder pour le bien de la descendance, et dans ces prières-là, la reine était naturellement partie prenante. On a vu ce sentiment paternel s'exprimer bien avant l'accession au trône. En juillet 1456, le retable sculpté offert à la chapelle de la Sainte-Baume comprenait, pour la première fois, une figure de la dauphine. Le nouveau couple apparaissait donc en priant de part et d'autre de la Madeleine. Que pouvait bien contenir les invocations de ces deux statues d'albâtre à Marie-Madeleine emportée au ciel par quatre anges ? À la fin de sa vie, Louis XI évoquait des «veu et promesse » ayant abouti à «plusieurs grans graces, que Dieu, nostre créateur, nous a par son intercession et prière, faictes et octroyées ». Il demandait à Madeleine d' "interceder de plus en plus, envers notredit Sauveur Jesus-Christ, pour nous, notre prospérité, et lignée, la santé de nostre personne, de nostre très chere et très amée compaigne, la royne $\gg{ }^{162}$. Ne retrouve-t-on pas dans les prières d'un monarque mourant celles de l'ambitieux dauphin ? Pourquoi «prospérité », «lignée » et santé de l'épouse auraient été absentes des plaidoyers du dauphin devant une sainte dont la légende rapportait qu'elle avait miraculeusement suscité un enfant au consul de Marseille et qui était vénérée par les jeunes époux en mal d'enfants ${ }^{163}$. Je pense que ce premier don commun était lié dans l'esprit de Louis à l'espérance d'un fils.

Durant le séjour brabançon, le couple delphinal se rejoignait pour le culte de saint Adrien dont les reliques étaient conservées dans l'église abbatiale de Grammont en Brabant. Ils apparaissent tous deux sur une enluminure tardive en prière devant un autel dédiée à Adrien. Ils sont agenouillés devant un prie-Dieu, face à face. Louis XI est dans la position du priant mains jointes, tandis que Charlotte maintient les pages d'un livre d'Heures. Chacun d'eux est présenté par un ange aux personnages d'un grand retable, offrant à leur dévotion commune non seulement saint Adrien au centre mais aussi saint Jean-Baptiste et saint Louis ${ }^{164}$. C'est bien dans cette symétrique et traditionnelle mie en scène que Charlotte participe à la piété royale dans les images ; c'est ainsi qu'elle figure sur le fameux ostensoir en orfèvrerie de Notre-Dame de Hal, en Brabant. Cette fois, Charlotte est en priant, les mains jointes, dans une attitude qui reflète exactement celle de son époux. De ses mains s'envole un phylactère avec des inscriptions évoquant le péché originel et la rédemption ${ }^{165}$. Elle joint ses prières à Louis au-dessous d'un soleil mystique destiné à contenir le Saint-Sacrement, environné par les noms des apôtres, les images du Tétramorphe, des quatre Docteurs de l'Eglise et de Marie et Jean l'Evangéliste. Depuis Hal le dauphin avait écrit plusieurs lettres pour annoncer la naissance de Joachim et il est vraisemblable que cette pièce fut offerte à l'église Notre-Dame dans le joyeux contexte de l'été 1459.

Onze ans plus tard, Charlotte ayant été délivrée d'un fils viable, elle venait en pèlerinage au sanctuaire angevin du Puy-Notre-Dame. Pendant sa grossesse, son époux avait fait à ce sanctuaire détenteur de la «Ceinture de la Vierge », relique sensée favoriser la naissance d'enfants mâles, un vœu pour obtenir un descendant ${ }^{166}$. Le roi avait même suscité, dans l'hiver 1469-1470, les prières

\footnotetext{
${ }^{160}$ Ibidem, t.X, n²142, p.443-444, 26 juin 1483 ?, à François de Genas. Commynes, t.II, p.83, n.3.

${ }^{161}$ Heers, p.339-340.

${ }^{162}$ Faillon, t.II, n²49, p.1323-1326, jan. 1483 (n.st.)

${ }^{163}$ Ibidem, t.I, p.1135. Desvignes-Mallet, art. cit., p.35, 61 : en 1244 Louis IX avait déjà rendu grâce à Madeleine de la naissance d'un fils.

${ }^{164}$ C.-Brouquet, p.44 et ill. 2.

165 Ibidem, p.207-211.

${ }^{166} \mathrm{M}^{\mathrm{is}}$ de la Franquerie, La Vierge Marie dans l'histoire de France, Fontenay-le-Comte, 1939, p.115. C.-Brouquet, p.189-190
}

Frizet Yannick

Page 16

$09 / 06 / 2019$ 
de ses sujets pour obtenir ce fils. Charlotte avait embrassé le culte romain de sainte Pétronille, fille légendaire de saint Pierre, et le couple royal aurait régulièrement recours à son intercession pour la santé du dauphin ${ }^{167}$. Louis XI rendait grâce à Notre-Dame d'Evreux en Normandie alors que Charles était nouveau-né. Dans le bras sud du transept, il se faisait représenter en priant devant une Vierge à l'Enfant tandis que la reine et le dauphin n'étaient présents que par leur écu ${ }^{168}$. La période 1470-1483 qui correspond à l'enfance du dauphin Charles s'avère particulièrement faste pour les représentations familiales. Les images de la piété conjugale, ou tout autre expression de celle-ci, apparaissent cependant exclusivement liées aux intérêts du dauphin. Vers 1475 sur un reliquaire d'argent et de vermeil offert à l'église des Saints-Innocents de Paris, les figures de Louis et Charlotte jouxtaient celles de saint Charlemagne et de saint Louis devant un «innocent tout entier en chair et en os » évoquant sans doute le jeune dauphin ${ }^{169}$. Du côté de Limoges, en 1475 se terminait les travaux de l'église Notre-Dame-du-Pont de Saint-Junien, engagés par le roi dès 1463. Sur les contreforts du portail deux niches étaient prévues, probablement pour les statues du couple royal $^{170}$. L'écu de la reine se voyait dans de nombreuses provinces du royaume, dans des sanctuaires plus ou moins modestes, comme dans le collatéral sud de Notre-Dame-de-Nantilly, à Saumur en Anjou, accosté de l'écu du dauphin ${ }^{171}$, sur un vitrail de Saint-Martin-aux-Jumeaux d'Amiens, en Picardie, avec les armes du roi et celles du dauphin ${ }^{172}$, et sur le portail de l'église Notre-Dame de Nanteuil, à Montrichard en Touraine, portés par un ange à l'instar de celui du roi ${ }^{173}$. Une place dans la piété royale est également ménagée pour la reine lors de fondation de messes. Nous l'avons déjà évoqué pour la Sainte-Baume mais l'exemple est loin d'être unique. En avril 1482, Louis XI établissait une rente de 4.000 1.t. aux religieux de Cadouin, dans le Périgord, afin de célébrer une messe chantée et réciter une oraison pour le roi, le dauphin, la reine et le salut de ses prédécesseurs. Le même mois, il confessait avoir souvent prié Dieu à l'abbaye de Pontigny, pour sa santé mais aussi pour la reine et le dauphin ${ }^{174}$.

Louis a couramment associé la reine à ses actes de piété, doublant ses propres prière de celles de son épouse, comme s'il eut souhaité les rendre plus efficaces pour obtenir la grâce d'un héritier pour le royaume de France. La piété conjugale s'exprimait ainsi dans plusieurs provinces, notamment celles que les époux royaux ont fréquentées : Brabant, Touraine, Anjou, Ile-de-France, mais aussi en Normandie, Limousin, Périgord, Champagne, Picardie et Provence. Louis ne semble pas avoir prié exclusivement pour le salut de Charlotte. La reine de France était incorporée, par nécessité, dans les intentions de prières pour la postérité du royaume.

\section{Le gardien du dauphin Charles}

La descendance masculine a été à l'évidence l'une des grandes préoccupations de la vie de Louis XI, et non le moindre des ressorts de sa foi. Dès le delphinat, en dotant le sanctuaire perché dédié à Marie-Madeleine en 1456, il songeait à sa postérité, comme je le crois. Il s'apprêtait à accueillir sa nouvelle épouse, laquelle devenait nubile. En juillet 1459, la naissance de Joachim comblait ses attentes comme on peut le deviner à ses lettres réjouies. Il en informait sur le champ le roi et quelques grandes institutions de la couronne, comme si la naissance d'un fils eut été une habilitation à gouverner et un avantage sur Charles, le frère rival. Quelques mois plus tard, l'enfant décédait et l'espoir était perdu. On lui aménageait néanmoins une belle sépulture dans l'église

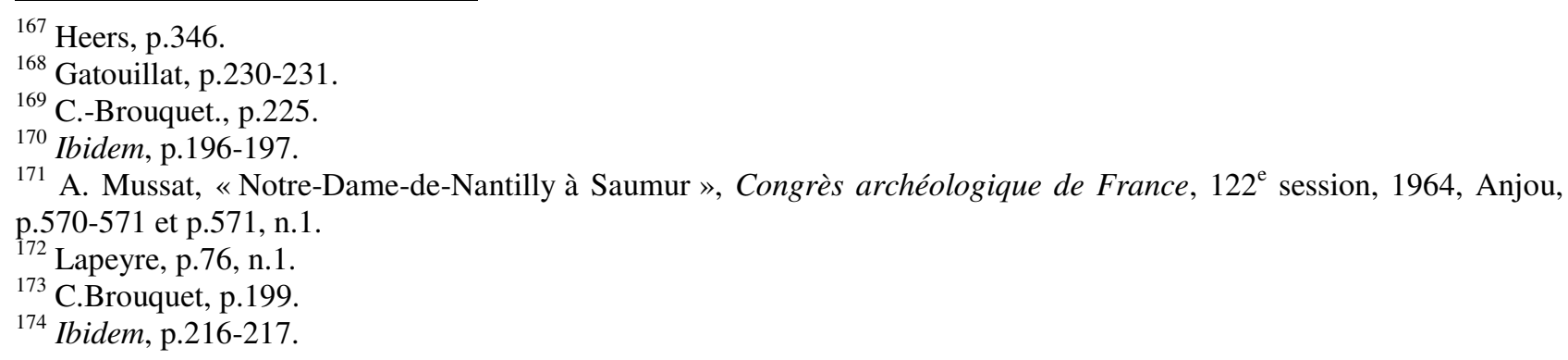


Notre-Dame de $\mathrm{Hal}^{175}$. Louis attendrait sept années avant de connaître semblable satisfaction. Elle s'éteindrait au bout de quelques heures, en décembre 1466, avec la vie du petit François. Dans le royaume de Louis XI, l'on priait en 1468 pour la «prospérité du roi et de ses successeurs », bien qu'il n'y eut alors aucun fils pour assurer cette succession ${ }^{176}$. Quatre années passeraient avant la naissance d'un nouveau fils, Charles, le 30 juin 1470 à Amboise. Il passait ses premières années auprès de sa mère Charlotte, ses sœurs Anne et Jeanne, ses cousins de la maison de Savoie Charles et Anne. Mais Louis XI semble avoir investi sa confiance dans le dernier fils que la reine lui donna en octobre 1472 : François, deuxième du nom. À ce fils cadet, Louis XI donnait le duché de Berry et offrait un blason sur la verrière d'une église normande. L'ouvrage dans l'église Notre-Dame de Saint-Lô, daté d'entre l'automne 1472 et l'été 1473, faisait s'illuminer les armes de François au même niveau que celles du dauphin Charles ${ }^{177}$. Le roi exposait à la vue de tous, dans une province récemment mâtée ${ }^{178}$, les deux fils qui garantissaient l'avenir du royaume de France. Au Puy-NotreDame, en Anjou, François apparaissait figuré en une statue d'argent auprès de son père et de son frère aîné ${ }^{179}$. Malheureusement François décédait en septembre 1473. Son père quittait le château d'Amboise, restant muet pendant six heures ${ }^{180}$.

Après la perte de trois fils, Charles demeurait seul à pouvoir combler les espérances de Louis XI. Non seulement le roi le protègerait désormais comme son plus grand trésor, mais il lui vouerait les meilleurs soins pour maintenir sa faible constitution physique. On tremblait dès l'hiver 1471$1472^{181}$ pour la santé du nourrisson, puis à nouveau dans le courant de $1475^{182}$ et encore en juin 1476 lorsqu'une probable pneumonie ${ }^{183}$ manquait de l'emporter à l'âge de six ans. En octobre, Louis soupçonnait un complot du duc de Nemours pour s'emparer de sa personne et de celle du dauphin. Le duc était déjà emprisonné dans une cage et son geôlier avait la consigne de « le faire gehenier bien estroit ${ }^{184}$. Que le personnel chargé du service de son «trés cher et trés amé filz le daulphin de Vyennoys » fût inquiété par la justice et le roi écrivait au Parlement qu'on le déchargeât au plus tôt ${ }^{185}$. Louis XI avait mis en place autour du dauphin un dispositif de sureté absolue dont il ne supportait qu'il pût faillir. Les sacrifices financiers qu'il exigeait de ses généraux des finances et trésoriers ne devaient en aucun cas grever le budget de son fils, pas plus que celui de sa femme ${ }^{186}$. Trois des conseillers les plus fidèles du roi étaient commis à la garde rapprochée du dauphin : Jean Bourré gouverneur du dauphin depuis 1478, Etienne de Vesc et Imbert de Batarnay ${ }^{187}$. Lorsque le roi souhaitait qu'un fidèle accédât à Amboise auprès du dauphin, il en donnait préalablement consigne à Bourré ${ }^{188}$. Assistant au déclin de sa propre santé, Louis XI redoublait d'attention pour

\footnotetext{
${ }^{175}$ C.-Brouquet, p.44 et ill. 1.

${ }^{176}$ P. de Thorey, t.II, $\mathrm{n}^{\circ} 1515$, p.144 et n.1 : engagement pris par le chapitre de Saint-André de Grenoble pour remercier le roi de plusieurs faveurs.

${ }^{177}$ Lapeyre, p.15 et n.9 p.15-16. C.-Brouquet, p.66-67.

178 Basin, t.I, p. 249-267 évoque les manœuvres de Louis XI en déc. 1465 pour reprendre la Normandie. Il l'avait naguères cédée à son frère Charles de France pour la résolution du Bien public.

${ }^{179}$ Lapeyre, p.80.

${ }^{180}$ L.-Mailfert, p. 18 .

${ }^{181}$ D'après le vœu que Louis XI formula à sainte Pétronille de Rome (G. Perinelle, « Louis XI bienfaiteur des églises de
} Rome » dans Mélanges d'archéologie et d'histoire, XXIIIe année, jan.-juin 1903, Ecole française de Rome, p.138-139).

${ }^{182}$ D'après un vœu du roi rapporté dans Heers, p.347 et n.98.

${ }^{183}$ L.-Mailfert, p.16.

${ }^{184}$ Lettres, t.VI, p.88-91, $1^{\text {er }}$ oct. 1476. L.-Mailfert, p.20, évoque cette inquiétude à partir de 1481 seulement. La missive citée semble la faire plus précoce de quatre ans.

${ }^{185}$ Ibidem, t.VII, p.105-106, 29 juin 1478.

${ }^{186}$ Ibid., t.VII, p.157-159, 8 sept. 1478.

${ }^{187}$ L.-Mailfert, p.19.

${ }^{188}$ Lettres, t.VIII, p.316 : le 16 nov. 1480, il informait Bourré de laisser Aymar de Poitiers accéder au dauphin. Louis ne manquait pas d'être généreux envers eux comme on le voit avec ce don à Etienne de Vesc en 1480, "pour ce que ledit de Vesc est celuy des serviteurs de nostredit filz qui plus est continuellement nuit et jour occupé pour la seurté de sa personne » (Ibidem, t.VIII, p.283-285, 25 oct 1480). Voir aussi t.X, n¹824, p.20-21, 23 nov. 1482, où Louis XI faisait appeler Etienne de Vesc auprès de lui si la santé du dauphin ne requérait plus sa présence. Louis XI naguère si nomade, élisait domicile dans le château du Plessis; et la présence du dauphin Charles à Amboise, c'est-à-dire à quelques lieues de là, n’y était pas étrangère. Comme il le faisait pour lui-même au Plessis, il barricadait l'accès au château d'Amboise 
celle du dauphin ${ }^{189}$. En février 1483, un vent d'ouest soufflait sur la vallée de la Loire, faisant craindre à Louis pour les fragiles poumons du dauphin. Il s'en remettait à Dieu, curieusement, par le truchement de ses officiers de la Chambre des comptes. Il leur ordonnait de faire «procession » jusqu'à Saint-Denis, "prieres et oraisons envers Dieu », afin de conjurer le vent et de «preserver et maintenir en bonne santé » le dauphin ${ }^{190}$.

On ne sait si la profusion de soins relevait davantage de l'affection paternelle que de la nécessité gouvernementale. Simultanément, Louis XI préparait l'entrée en fonction de sa créature. Depuis 1473, il hésitait sur le meilleur mariage à conclure pour l'avenir du royaume ${ }^{191}$. Les fiançailles avec la petite Marguerite d'Autriche était célébrées au château d'Amboise le 22 juin 1483, en présence du roi mourant ${ }^{192}$. À partir de 1482, le dauphin de douze ans se voyait initié par son père aux responsabilités de l'État. En avril, il était chargé d'accueillir à Tours l'ermite François de Paule que son père avait attiré à lui ${ }^{193}$. En mars 1483 , le roi faisait «escrire au Pape par

et au dauphin (L.-Mailfert, p.20-21. Commynes, t.II, p.76). Malgré sa constante implication dans la vie quotidienne du dauphin, le roi malade n'est plus venu à Amboise pendant sept années (Lettres, t.XI, Itinéraire, p.137-210. D'après les lettres répertoriées, Louis XI a quitté Amboise pour la dernière fois en décembre 1473 et n'y est revenu qu'en décembre 1480). Mieux valait que le dauphin «ne feust veu de gueres de gens, tant pour la santé de l'enfant que de paour que l'on ne le tirast hors de là, et que soubz umbre de luy quelque assemblée ne se fist en son royaulme » (Commynes, t.II, p.69).

${ }^{189}$ En juillet 1480, un nouveau médecin de Charles était choisi par le roi, Jean Martin (Lettres, t.VIII, p.242, 27 juil. 1480). Charles semble avoir attrapé une toux inquiétante à l'automne 1480. Le roi, identifiant la cause du mal, interdisait formellement en novembre qu'on ne l'emmenât " aux champs », c'est à dire au grand air, avant février prochain. Les communications devaient, en pareil cas, être multipliées : « et me mandez demain au matin coment il cest porté ceste nuyt » (Ibidem, t.X, n²129, p.429, 13 nov. 1480, au comte de Saint-Pol, au seigneur du Plessis et à Claude de Molins). Quelques mois plus tard, le dauphin souffrait toujours d'accès de toux et sa gouvernante était congédiée (Ibid., t.IX, p.58-59 et n.1 p.59-60, 20 juil. 1481, au seigneur du Bouchage).

${ }^{190}$ Ibid., t.X, n 1858, p.62-64, 3 fév. 1483, à la Chambre des comptes. Le roi précisait que la démarche visait aussi à « consoler et aider le pauvre peuple de nostre royaume... » La procession fut accomplie le 7 février suivant.

${ }^{191}$ En juin il envisageait l'union de Charles avec la fille du roi Ferrante d'Aragon, Béatrice (Ibid., t.V, p.146-149, 19 juin 1473, à Laurent de Médicis). En janvier 1475, c'était sa nièce Isabelle d'Aragon (L.-Mailfert, p.26), puis la même année la fille aînée du roi d'Angleterre Edouard IV, Elisabeth. L'alliance anglaise était utile dans la guerre contre la Bourgogne, mais malgré des fiançailles effectives suite au traité de Picquigny, on ne donna pas suite (Commynes, t.II, p.57). Mieux valait choisir directement une héritière de Bourgogne. Quelques jours après la mort du Téméraire en janvier 1477, Louis XI souhaitait rendre publique son intention de marier le dauphin à la fille du défunt, Marie (Lettres, t.VI, p.111-112 9 jan. 1477). Elle mourait peu de temps après, laissant une fille issue de son mariage avec Maximilien d'Autriche : Marguerite. Louis XI jeta son dévolu sur elle. Cette fois le mariage était une des clauses du traité de paix entre la France et le duc d'Autriche, signé à Arras en décembre 1482 (Heers, p.82). Pour le roi déclinant, « la chose est fort hastive et requiert grant celerité »(Lettres, t.X, p.27-31, n¹831, 3 déc. 1482). Sur les préliminaires à ce mariage voir aussi Lettres, t.X, n 1838 , p.36-37, 18 dec. 1482, aux habitants de Compiègne ; ${ }^{\circ} 1841$, p.40-41, 21 déc. 1482 , aux habitants d'Amiens; n`1855, p.55-56, 3 jan. 1483, au Parlement ; n 1872 , p.83-85, 12 mars 1483, aux habitants de Saint-Quentin ; $\mathrm{n}^{\circ} 1873$, p.85-86, 17 mars 1483, à l'université de Paris. La future dauphine Marguerite, âgée de moins de trois ans, arrivait à la fin mai 1483 à Hesdin en Flandre, où elle était reçue par Anne de Beaujeu et son époux. Ils se rendaient ensemble à Paris où le mariage était prévu (Commynes, t.II, p.62, n.1, 3, 6). Louis XI était alors bien trop diminué physiquement pour se présenter mais il orchestrait à distance les évènements. Début juin, « obstant les grans chaleurs et dangiers de mortalité qui sont de present » à Paris, il transférait la cérémonie à Amboise où avait été maintenu le dauphin Charles (Lettres, t.X, n 1895 , p.115-116, 2 juin 1483).

${ }^{192}$ Favier, p.771-772. Le 10 juin, il réclamait encore aux Lyonnais l'envoi à Amboise de leurs délégués pour assister au mariage (Lettres, t.X, n¹898, p.119-120).

${ }^{193}$ Gandilhon, p.108-109. En septembre, Louis jugeait le moment propice pour instruire le dauphin sur le gouvernement du royaume. Pour la première fois depuis longtemps, il visitait Charles à Amboise afin de lui faire approuver quelques conseils politiques de prise en main de l'administration, lesquels conseils étaient rédigées sous forme de patentes en date du 21 septembre 1482 et diffusés pour entérinement aux parlements provinciaux (Lettres, t.IX, p.308-309, 21 sept. 1482, au Parlement et à la Chambre des comptes de Bourgogne ; voir Ordonnances, t.XIX, p.56). Le texte intégral des Instructions à son fils sur l'administration du royaume a été publié dans Gaussin, p.440-444). L'enfant jurait à son père, la main levée, qu'il respecterait à la lettre ses Instructions. Un mois plus tard, devant le Conseil royal, il contresignait avec grande émotion les ordonnances royales sur le sujet, lui qui avait toujours été protégé du monde extérieur et des fatigues de l'étude (Commynes, t.II, p.69-70. L.-Mailfert, p.21-24). Charles avait douze ans et participait pour la première fois au Conseil royal (Gaussin, art. cit., p.107, 126). Désormais, Louis XI mettrait le sceptre dans la main du dauphin. Dès novembre 1482, des lettres royales annonçaient que c'était « Mons ${ }^{\mathrm{r}}$ le daulphin » qui décidait de la 
Monseigneur le Daulphin » au sujet du bénéfice vacant de feu Guillaume d'Estouteville, cardinal de Rouen. Il demandait à son chancelier que les lettres fussent scellées du « contre sceau du Daulphiné ${ }^{194}$. Enfin, le 30 août 1483, la mort ayant donné son signal, Louis XI faisait transférer d'urgence les principaux du gouvernement et sa garde à Amboise. Quelques heures avant sa mort, il allait jusqu'à envoyer à celui qu'il appelait déjà le « Roy son filz » les sceaux qu'il avait fait graver pour le règne de son successeur ${ }^{195}$.

Pour la bonne accession du dauphin Charles au trône, Louis XI avait naturellement grand besoin de l'intercession divine. Pendant les treize dernières années de sa vie, il activait quasiment toutes les capacités dévotionnelles du royaume de France et au-delà. De ce «grand œuvre » de dévotion, je me propose ici d'indiquer ici quelques étapes, sans viser à une étude exhaustive qui dépasserait les limites d'un article. Dès avant la naissance de Charles, Louis se tournait vers le PuyNotre-Dame. Charlotte était enceinte lorsqu'il y faisait le vœu au cours du pèlerinage d'avril 1470, d'offrir une statue d'argent du dauphin si un fils viable lui était donné. Immédiatement après la naissance, exaucé, il respectait son vœu et revenait deux fois en pèlerinage en juillet et août 1470, faisant un don de 160 écus d'or pour la statue promise. Celle-ci figurait le nourrisson tel qu'il était alors, c'est-à-dire âgé de deux mois. Mais le roi la ferait « réactualiser » en janvier 1475 pour 750 1.t., le dauphin ayant atteint l'âge de quatre ans et demi. La statue de 1475 devrait à son tour être remplacée lorsque le dauphin atteindrait sa dixième année. Louis XI s'en souciait en 1480 et prévoyait un financement de plus de 843 écus d'or l'année suivante ${ }^{196}$. Cette dernière statue ne semble pas avoir été mise en place. La figure de Charles était intégrée à un groupe de quatre statues d'argent, celle du roi et de deux de ses fils, le tout fixé sur un socle fleurdelisé et garni d'objets de même métal ${ }^{197}$. L'on y contemplait l'unité de la fratrie royale autour du père, s'étendant par-delà la mort même, et dans le culte de la Vierge. La fidélité de Louis XI aux âmes de ses défunts fils apparaît, fait insolite, comme étrangère aux nécessités dynastiques. Louis souhaitait que Charles entretînt ce don d'argent évolutif par lui-même tous les dix ans; il le lui faisait promettre sur parchemin. Dans les lettres de don de févier 1481, il parlait à son maître des comptes du « vœu de monseigneur le Dauphin » ${ }^{198}$. En 1476, c'était un artisan qualifié d' « orfèvre du dauphin », Robin Porchier, qui réalisait un placage sur le tabernacle de l'autel ${ }^{199}$. L'initiative de l'acte de dévotion devait revenir au plus tôt à l'enfant promis au trône. Bien avant de songer à une formation politique, Louis XI lui tenait la main, dès l'âge de six ans, pour faire un don à la Vierge. Cela ne dispenserait pas Louis XI d'accumuler les libéralités au Puy-Notre-Dame, rendant régulièrement grâce des guérisons du dauphin ${ }^{200}$.

Peu après la naissance de l'enfant tant désiré, il donnait une verrière à Notre-Dame d'Evreux, en Normandie. L'on y voyait le blason du dauphin ${ }^{201}$ comme produit par l'effet du roi en

\footnotetext{
libération d'un certain «messire Lancellot» (Lettres, t.X, n¹826, p.23, 24 nov. 1482). En janvier 1483, Charles assistait auprès de son père aux pourparlers avec les ambassadeurs de Flandres (Commynes, t.II, p.61, n.3).

${ }^{194}$ Lettres, t.X, n¹870, p.81, 4 mars 1483.

195 Commynes, t.II, p.70-74. M. Pastoureau, Corpus des sceaux français du Moyen Age, t.II, Les sceaux des rois et de régence, Paris, Archives nationales, 1991, p.33.

${ }^{196}$ Lettres, t.IX, p.9-10, 21 fév. 1481, à Bourré : «pour le pesant et ung an advantaige de Mons ${ }^{\mathrm{r}}$ le dauphin, qui, Dieu mercy et Nostre Dame, est en trés bon point ».

${ }^{197}$ Lapeyre, p.80-82. La statue la plus lourde des quatre était celle du dauphin Charles, pesant quinze marcs de plus que celle de Louis XI sans ses accessoires. Quant aux enfants représentés, l'un d'eux était certainement François deuxième du nom qui vécut en 1472-1473. Le second était représenté en langes à titre posthume. Il pouvait s'agir de Joachim, qui vécut quelques mois en Brabant en 1459 ou de François premier du nom, fils du roi, qui ne vécut que quelques heures en 1466.

${ }^{198}$ Lettres choisies, n574, p.509-510.

${ }^{199}$ Lapeyre, p.43.

${ }^{200}$ Ibidem, p.35, 37 et n.10, 38, 43, 76 et n.7 : un calice de vermeil émaillé, un reliquaire de vermeil pour contenir la Sainte Ceinture, deux lampes en argent en 1477, un ostensoir figurant la Sainte-Chapelle de Paris, préfigurant la création d'un chapitre royal. Pour les abandons de droits voir Lettres, t.VIII, p.305-306, 9 nov. 1480, au Parlement : le roi précisait : «c'est pour noz veuz, et que pour riens ne vouldrions qu'il y eust faute. »

${ }^{201}$ Gatouillat, p.230-231.
} 
prière devant la Vierge à l'Enfant. À Chartres, Notre-Dame-de-sous-Terre entendait elle aussi le vœu du roi en faveur du dauphin ; pour quoi Louis offrit en janvier 1471, un tabernacle peint « à la pourtraicture et semblance de Monseigneur le dauphin » pour abriter la Vierge noire ${ }^{202}$. En octobre 1472, il accordait des privilèges à Notre-Dame de Celles, en Poitou, notamment pour la prospérité $\mathrm{du}$ roi, du dauphin et de ses autres enfants ${ }^{203}$. À l'hiver 1471, Charles connaissait des ennuis de santé et le couple royal se vouait à sainte Pétronille de Rome, vénérée comme la fille de saint Pierre. En échange de la guérison du dauphin Charles, Louis s'engageait à faire restaurer la chapelle de la sainte dans la basilique Saint-Pierre et à y fonder deux chapellenies. Exaucé, il accomplissait un don de 1200 1.t. pour les travaux, ajouté aux sommes déposées en banque pour la fondation promise, laquelle n'aboutirait qu'après la mort du donateur, sur les instances de Charles VIII ${ }^{204}$.

Le culte particulier de Louis XI pour les Saints-Innocents et ses libéralités aux sanctuaires en détenant des reliques sont à mettre en rapports avec les prières paternelles. On remarque d'ailleurs que les offrandes surviennent sous le coup des affections du petit dauphin. En 1471-1472, le roi offrait un reliquaire d'argent en forme de berceau au Saint Innocent de l'église Saint-Saturnin d'Avranches; un autre reliquaire était donné aux Saints-Innocents de Paris en 1474-1475, un troisième au Saint Innocent de l'église Saint-Just de Lyon en $1476^{205}$.

Mais on ne saurait limiter à cela les bienfaits royaux au nom du fils, d'autant qu'ils connaîtraient une croissance hyperbolique après le décès de François en 1473. L'année 1475 était néfaste pour la santé du dauphin, poussant les vœux de son père à la recrudescence. En avril 1475 Louis XI alimentait les prières en Normandie par un don de 1200 écus à Notre-Dame de Rouen ${ }^{206}$, et en Dauphiné par un don de 1200 1.t. de rente annuelle à l'abbaye de Saint-Antoine-en-Viennois. Il demandait à ce que «monseigneur saint Anthoine soit intercesseur et advocat envers nostre dict Créateur pour nous, nostre très cher et très amé fils Charles, daulphin de Viennois, et nostre postérité et lignée ${ }^{207}$. Autre vœu du roi à Notre-Dame-de-Salles, à Bourges, en septembre 1475, impliquant, comme au Puy-Notre-Dame, le pesant d'argent du dauphin ${ }^{208}$. En janvier 1476, c'était un portrait du dauphin que l'on faisait peindre dans Notre-Dame de Chartres ${ }^{209}$. En 1478, tôt après l'annexion du duché de Bourgogne, les verrières de la Chambre des comptes de Dijon, présentaient les blasons du roi et du dauphin portés par des anges ${ }^{210}$. Parallèlement à la reprise en main de l'apanage, les armes brisées de Bourgogne s'effaçaient devant les armes pleines de France, celles-ci souvent accostées des armes du dauphin ${ }^{211}$. Manifestement les deux emblèmes allaient systématiquement de pair. En juin 1479, la cathédrale de Meaux pouvait les contempler sur la nouvelle châsse offerte par Louis $\mathrm{XI}^{212}$. À l'hiver 1480-1481, probablement juste après les toux inquiétantes de Charles, les comptes mentionnent des offrandes suite à un nouveau vœu pour le dauphin $^{213}$. Dans les mêmes circonstances, il faisait porter 2000 ducats d'or à Sainte-Catherine du Sinai ${ }^{214}$. Dans les dernières années, Louis XI s'efforçait de retarder l'échéance de sa propre mort en même temps qu'il portait par sa foi la santé de son fils. Car le roi continuerait à prier pour sa propre

\footnotetext{
${ }^{202}$ C.-Brouquet, p. 193.

${ }^{203}$ Ibidem, p.191-192.

${ }^{204}$ Perinelle, art. cit., p.138-140. L’hypothèse est formulée que ses libéralités pour la construction de l'église et du couvent de Saint-Pierre in Montorio découleraient aussi de la guérison du dauphin (p.143-144 et 146).

${ }^{205}$ Lapeyre, p.54-55.

${ }^{206}$ Lettres, t.V, p.331, 1 er avril 1475, au chapitre de Rouen : «pour l'augmentacion de la fondacion de ladicte église, en nous ayant tousjours, nous, nostre filz le daulphin, en voz bonnes prieres envers Dieu et ladicte dame pour recommandez. »

${ }^{207}$ P. de Thorey, t.II, ${ }^{\circ} 1620$, p.208, avril 1475.

${ }^{208}$ Heers, p.347 et n.98.

${ }^{209}$ C.-Brouquet, p.206.

${ }^{210}$ Ibidem, p.79.

${ }^{211}$ Heers, p.81.

${ }^{212}$ C.-Brouquet, p. 220.

${ }^{213}$ M.L.Douët-d'Arcq, Comptes de l'hôtel des rois de France aux XIVe et XVe siècles, Paris, 1865, p.387 : «- Pour partie des offrandes par lui (le Roi) voeés (sic) et promises durant la maladie de monseigneur le Dauphin (fol. $121^{\mathrm{vo}}$ ). » novembre 1480-janvier 1481.

${ }^{214}$ Lapeyre, p. 14.
} 
guérison jusqu'au bout. Pour Charles, il sollicitait encore en 1478-1479 les prières des moines de Saint-Edme de Pontigny ${ }^{215}$, en juillet 1480 celles des religieux de Notre-Dame de Salvation, à Compiègne $^{216}$, à partir de janvier 1482 celles des chanoines de Notre-Dame d'Embrun ${ }^{217}$, en mars 1482 les prières des moines de Saint-Claude ${ }^{218}$, celles des chanoines de Sainte-Marthe de Tarascon, dont le collège était une fondation royale de mai $1482^{219}$, des moines de Cadouin en avril $1482^{220}$ ${ }^{221}$, des religieux de Saint-Jacques de Compostelle et des chanoines de Cologne chargés d'invoquer les rois mages en juillet $1482^{222}$. Les armoiries du dauphin côtoyaient encore l'écu royal sur un vitrail de l'église Notre-Dame-des-Marais à la Ferté-Bernard ${ }^{223}$, sur une verrière de la collégiale Saint-Etienne d'Eymoutiers ${ }^{224}$, de Saint-Martin-aux-Jumeaux à Amiens ${ }^{225}$, sur les voûtes de NotreDame-de-Nantilly à Saumur ${ }^{226}$, ainsi que sur la châsse de Saint-Claude parmi quatorze blasons tous consacrés au roi et au dauphin ${ }^{227}$. L'effigie de Charles se voyait encore sur un vitrail de NotreDame de Béhuard, en Anjou ${ }^{228}$, et dans la cathédrale d'Embrun, en Dauphiné. En effet, les volets des orgues majestueuses offertes par le roi à date indéfinie, servaient également de panneaux d'exhibition de la filiation royale. À date encore indéterminée, l'un des volets était peint de l'image de Louis XI, et l'autre de l'image de Charles, tous deux en priant au-dessous de Notre Dame ${ }^{229}$.

Pour célébrer le projet de mariage de Charles avec Marguerite d'Autriche Louis XI commandait des processions dans les bonnes villes du royaume et notamment à Nîmes dès janvier 1483. La commune commandait alors une centaine de panonceaux aux armes du roi et du dauphin, lesquels seraient exhibés en musique et stimuleraient les exclamations de «vive le roi! " et "vive monseigneur le dauphin! ${ }^{230}$. En définitive, la filiation royale était introduite dans presque toutes les provinces du royaume, tel que Louis XI le remodèlerait (Touraine, Berry, Poitou, Ile-de-France, Champagne, Normandie, Languedoc, Dauphiné, Limousin, Périgord, Anjou, Bourgogne, Picardie, Maine, Provence). Une concentration singulière se note dans la zone de langue d'oïl (fig.4), en particulier dans le domaine direct (Ile-de-France, Normandie, Champagne). Le dauphin est également bien présent dans les pays annexés (Anjou, Maine, Bourgogne, Provence). Que l'on priât pour Louis XI et le dauphin Charles, que l'on les célébrât ou que l'on vît l'écu ou le portrait de l'un près de se substituer à l'autre, nul n'était censé ignorer le fait de la filiation du roi. Même les États européens comme le royaume de Castille, les États du pape, l'Empire germanique, et jusqu'au Moyen-Orient, étaient informés des bonnes chances de postérité de la couronne de France.

\footnotetext{
${ }^{215}$ Ibidem, p.13, n.7; p.97 et n.5.

${ }^{216}$ Lettres choisies, ${ }^{\circ} 506$, p.462, 18 juil. 1480.

${ }^{217}$ P. de Thorey, t.II, n 1793 , p.314, jan. 1482 (n.st.) ; nº1807, p.323-324, 6 juil. 1482 ; n 1813 , p.327-328, 23 sept. $1482 ; \mathrm{n}^{\circ} 1824$, p.335-336, 8 avril 1483.

${ }^{218}$ Lettres, t.IX, p.188-189, 11 mars 1482, à Pierre Gruel, président du parlement de Dauphiné : «affin qu'ilz prient Dieu et le benoist Mons ${ }^{\mathrm{r}}$ Saint Glaude pour moy et Mons ${ }^{\mathrm{r}}$ le daulphin, nostre prosperité et sancté » P. de Thorey, t.II, p.316-317, $\mathrm{n}^{\circ} 1795$ et n.1 p.317. Pour les cessions de droits à l'abbaye voir Heers, p.344.

${ }^{219}$ Faillon, t.I, p.1254 -1255 et p.j. t.II, n²51, p.1329. L’on y apprend que Marthe faisait partie des saints auxquels Louis XI se vouait pour obtenir la guérison du dauphin.

${ }^{220}$ C.-Brouquet, p.216-217.

${ }^{221}$ Lapeyre, p.13, n.7; p.97 et n.5.

${ }^{222}$ Heers, p.347 et n.99. Commynes, t.II, p.53-54 énumère quelques dons matériels supplémentaires de Louis XI dans lesquels il faudrait encore rechercher des images.

${ }^{223}$ Lapeyre, p.16. et n.8.

${ }^{224}$ C.-Brouquet, p.69.

${ }^{225}$ Lapeyre, $74-76$ et p.76, n.1.

${ }^{226}$ Mussat, art. cit., 1964, p.571 et n.1.

${ }^{227}$ Lapeyre, p.62-64. C.-Brouquet, p.223.

${ }^{228}$ C.-Brouquet, p. 188.

${ }^{229}$ M. Fornier, Histoire générale des Alpes maritimes ou cottiènes et particulière de leur métropolitaine Ambrun, publiée par l'abbé Paul Guillaume, v.1640, Paris, 1891, t.II, p.391-392.

${ }^{230}$ P.-L. Baragnon, Abrégé de l'histoire de Nîmes, Nîmes, 1831, rééd. Nîmes, 1984, p.307 et 309. Délibérations communales du 15 janvier 1483 .
} 
Les lettres de Louis XI nous apprennent combien il respectait son père, combien il se sentait proche de son oncle et vassal René d'Anjou-Provence, combien il avait d'affection pour la reine Charlotte et enfin combien il prisait la vie de son fils Charles. Mais ces propos qui s'expriment de manière quasi-ininterrompue correspondent assez mal aux faits. Cette parallaxe révèle la grande duplicité d'un homme dans la position d'un chef d'État. Le pire opposant de Charles VII, devenait, une fois roi, le continuateur des grands axes de sa politique de gouvernement et le protecteur de sa progéniture extraconjugale. Il se faisait l'écho, même amplifié, du programme de dévotion et de munificence de son père à travers le royaume. Louis XI a pris mieux soin de l'âme, à titre posthume, que de la personne de Charles VII. En tant que prédécesseur, sa mémoire était incontournable aux yeux d'un roi qui accordait tant d'importance à la dynastie. D'ailleurs, dès l'exil dauphinois, Louis avait consacré des prières aux précédents dauphins de Viennois ${ }^{231}$. La continuité princière surpassait au besoin la filiation.

Le si proche neveu de René d'Anjou était celui qui portait un coup fatal à tous les intérêts angevins en Europe. À une exception près, à Tarascon et de façon lointaine, leurs « offertes » ne s'unissaient jamais. Au contraire, dans les pays angevins que Louis XI convoitait, comme le comté de Provence, la munificence des deux princes connaissait une sorte de rivalité. En Anjou, le roi multipliait les dons et les pèlerinages au sanctuaire de Puy-Notre-Dame en 1470. L'époque correspondait certes à la naissance du dauphin Charles, mais aussi à une volonté d'écarter le duc René et d'empiéter sur le duché vassal. Louis XI ne priait pas avec son oncle mais chez lui, et la proximité des liens du sang étaient telle qu'il a fini par se substituer à lui. Après quoi l'on vit à Paris et Angers le roi Louis songer au salut de l'âme de son oncle, ou plutôt, une fois de plus, de son prédécesseur au duché d'Anjou. Louis XI priait pour ceux qui lui avaient laissé leur bien.

L'époux attentif et généreux de Charlotte de Savoie ne partageait pas souvent sa vie. Incontestablement, Louis XI octroyait à sa femme tous les honneurs dus à son rang et lui accordait sa confiance pour sa fonction de mère. Mais la reine n'avait pas voix au chapitre de l'État, voyant son implication réduite à la représentation diplomatique ou spirituelle. Dans le domaine de la représentation de la famille royale à Dieu et à ses saints, Louis XI avait besoin d'une reine. Ainsi, Charlotte était participante ès œuvres pies du dauphin puis du roi, comme un catalyseur de postérité. On la voyait formant une paire de priants avec le roi dans plusieurs provinces du royaume et dans les terres du duc de Bourgogne où le couple avait vécu. Il arrivait que Louis XI priât pour la reine, l'incluant dans les prières lignagères que la maladie décuplait.

Le père angoissé pour son fils pouvait passer des années entières sans aucun contact avec lui. Louis XI n'a pas vu le dauphin Charles de l'âge de 3 ans à l'âge de 10 ans. Pourtant, nul objet n'a autant suscité d'actes de dévotion de Louis XI que le dernier dauphin. À chaque grossesse de la reine, il invoquait Notre Dame pour la naissance d'un fils. Les quatre fils de Louis XI eurent une part dans les prières de leur père, en proportion de la longueur de leur vie. Seul Charles survécut ; il occupa la meilleure part des pratiques cultuelles du roi. Chaque épisode de maladie du dauphin se repère à une recrudescence des dons à la Vierge et aux saints (1470-1471, 1475-1476, 1480-1481). Charles devenait le noyau d'un culte qui s'élargissait parfois aux prédécesseurs et aux successeurs, et parfois à la reine. Louis XI ne s'oubliait pas lui-même et priait à la fois pour la relève et pour le retardement de sa propre fin. Bien avant le supposé «testament politique » qu'il livrait au futur Charles VIII, il s'efforçait de lui transmettre un testament dévotionnel. À plusieurs reprises, il faisait représenter Charles en priant auprès de lui, comme l'initiant à une communion de prière envers Celle qui était tenue pour responsable de sa naissance et grande protectrice du royaume de France. Il faisait des dons au nom du dauphin bien avant de l'impliquer dans les décisions politiques.

Louis XI laisse l'impression, une fois encore, d'entretenir plus la couronne que le futur roi, la fonction que l'homme. Aux quatre parents dont il a été question ici, il attribue la même formule,

${ }^{231}$ P. de Thorey, t.I, ${ }^{\circ} 1046$, p.408, oct. 1453.

Frizet Yannick

Page 23

$09 / 06 / 2019$ 
affectueuse mais galvaudée par sa profusion, de «très cher et très amé ». Sans vouloir préjuger de la capacité affective de l'homme, on doit remarquer la transcendance de ses préoccupations pour la prospérité de la dynastie et de la couronne. Au-delà des personnalités qui ont été évoquées, et que le roi a plus ou moins recommandées à Dieu, se place l'intérêt du royaume. Louis XI ne manquait pas une occasion de rappeler qu'il agissait « pour le bon et grand vouloir que nous avons à la couronne et royaume de France, aux sujets et habitants d'icelui ${ }^{232}$. Il faudrait nuancer le portrait du « fondateur de la France moderne » en rappelant combien il a nui à son père et aux intérêts de ce même royaume, lorsqu'il était un dauphin $\operatorname{amer}^{233}$. Par ailleurs, Louis XI qui apparaît dans sa foi comme le fidèle observateur de la tradition française fut celui qui déclassa la grande abbaye royale de Saint-Denis, lui retirant le «sacré ministère » de rédiger les Chroniques de France ${ }^{234}$ et d'abriter la sépulture royale. Bien qu'empreint de la dignité royale, Louis XI ne fut pas le paisible continuateur de la tradition.

Enfin, quitte à reprendre des observations déjà anciennes de l'historiographie de ce roi, on doit insister sur le grand pragmatisme qui se profile derrière ses actes de piété ${ }^{235}$. Pragmatisme dans la spiritualité de celui qui a tant usé de la pratique du vœu et de l'action de grâce, ne dénotant pas en cela avec ses contemporains. La grâce divine se négociait moyennant une promesse de don à l'Eglise ; transaction que Louis XI pratiquait avec régularité, requérant une commutation de vœu du pape au cas où l'exécution du don était devenue impossible ${ }^{236}$. Pour chaque offrande le roi entendait « estre paiez de ce que avons donné » ${ }^{237}$. Pragmatisme aussi dans les prières qu'il accordait à ses proches selon leur capacité à participer à «l'entretènement» du royaume. Seule la fidélité de Louis XI aux âmes de ses défunts fils, manifestée au Puy-Notre-Dame, fait exception à la logique anticipatrice. Mais de façon générale, la communauté familiale de prière ne se retrouve aucunement au Conseil. Pour les décisions d'État, Louis XI compte beaucoup sur lui-même, avec l'aide divine.

Pragmatisme encore dans les lieux où s'exprimaient ses prières. Car la question du lieu du bienfait est centrale dans le vaste sujet de la piété d'un roi qui commue perpétuellement sa dévotion privée en une dévotion publique. La religion de Louis XI est une religion à partager avec les autres, j'oserais dire pharisaïque. Le monarque avait un intérêt évident à multiplier et diffuser dans toutes les provinces du royaume les vœux, les dons et les fondations en sa faveur et celle du dauphin. La promiscuité des figures ou des blasons de l'un et de l'autre permettait le glissement de la ferveur de l'un vers l'autre, et ainsi le transfert de loyauté. De même que l'induction de la pensée du roi et de sa famille dans les lieux de culte permettrait par extension la loyauté et la foi envers la dynastie. Car avec qui cherchait-il à partager sa piété dynastique si ce n'est avec ses donataires, le clergé, et à travers eux avec le peuple tout entier qui convergeait en masse vers les églises ? Louis XI concevait probablement les avantages qu'il tirerait en informant le peuple des villes et des campagnes qu'il était en mesure d'assurer avec la reine la postérité de la longue dynastie de France, qu'un dauphin venait de voir le jour, qu'il avait triomphé de la maladie, puisque les actions de grâce du roi intervenaient après les guérisons. Le peuple était même en mesure de connaître l'aspect physique du dauphin, à plusieurs moments de sa vie, jusqu'à l'âge de la majorité et de l'accès au trône. Par sa politique de munificence, Louis XI assurait une bonne couverture à sa « communication ». L'un des effets de cette politique touche à l'histoire de l'art et aboutit à un surcroît de naturalisme dans la représentation physique ${ }^{238}$. Un autre effet, beaucoup plus aligné sur la sagacité de Louis XI, a pu viser à consolider l'attachement du peuple à la maison de France et concourir à la naissance d'un sentiment national, bienvenu pour effacer les divisions de la Guerre de Cent ans.

\footnotetext{
${ }^{232}$ Lettres choisies, n559, p.499-500, 21 sept. 1482.

${ }^{233}$ Outre les évènements de la Praguerie, le dauphin s'est encore opposé à l'engagement militaire de Charles VII sur le terrain anglais (Heers, p.53).

${ }^{234}$ Favier, p. 195.

${ }^{235}$ Evoqué précocement et entre autres par Faillon, t.I, 1848, p.1000 et Périnelle, art. cit., 1903, p.147.

${ }^{236}$ Lettres choisies, $\mathrm{n}^{\circ} 579$, p.512-513.

${ }^{237}$ Lettres, t.X, n¹843, p.42-43, 22 déc. 1482, aux moines de Saint-Claude.

${ }^{238}$ Gandilhon, p.92.
} 


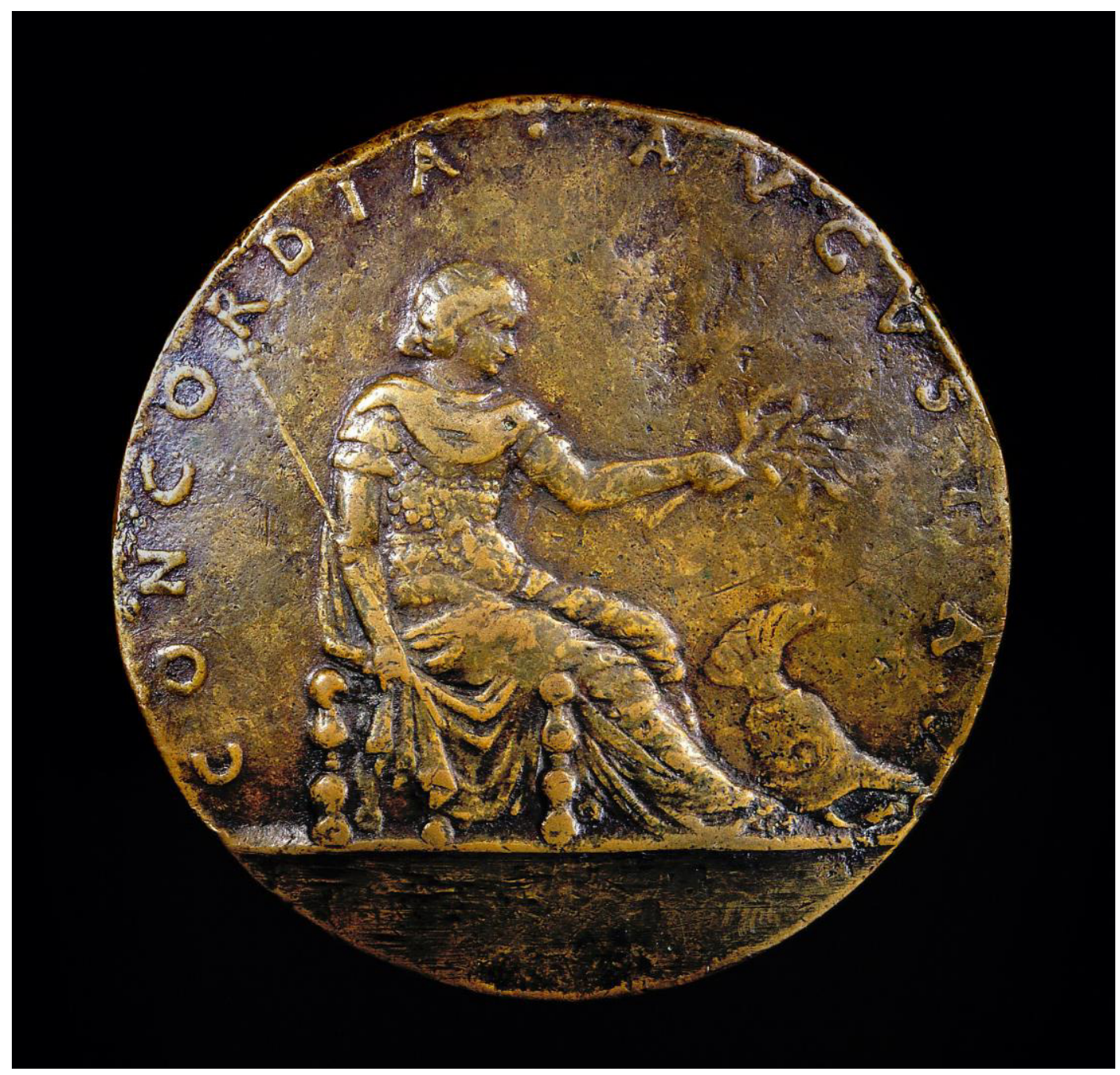

Fig.1 : médaille de la Concordia augusta, offerte par René d'Anjou à Louis XI en 1465 ?, B.n.F., cabinet des médailles, AV 144, revers. 


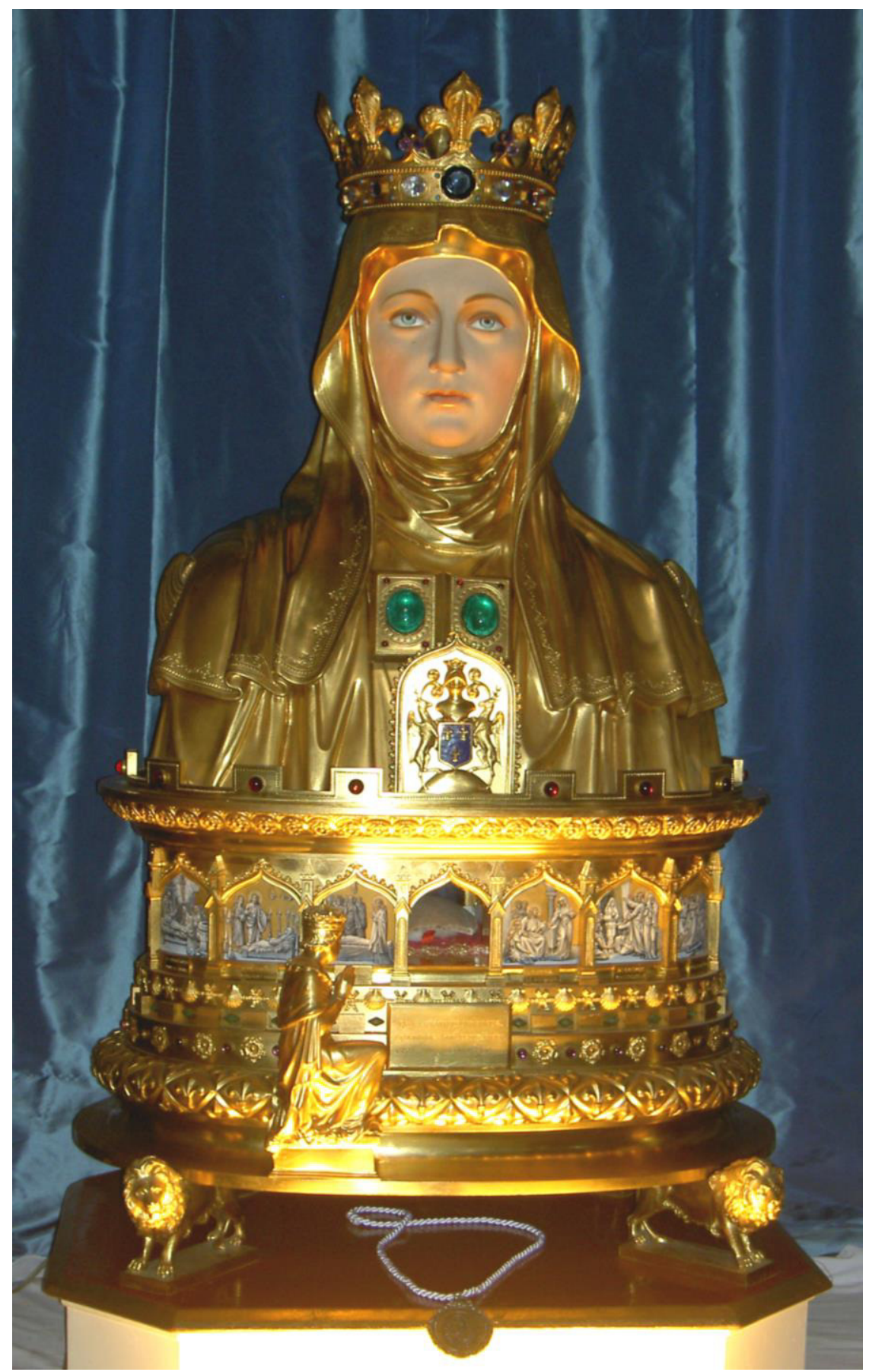

Fig.2 : buste-reliquaire de Sainte-Marthe de Tarascon, copie en bois doré du XIXe siècle, église Sainte-Marthe, Tarascon. 


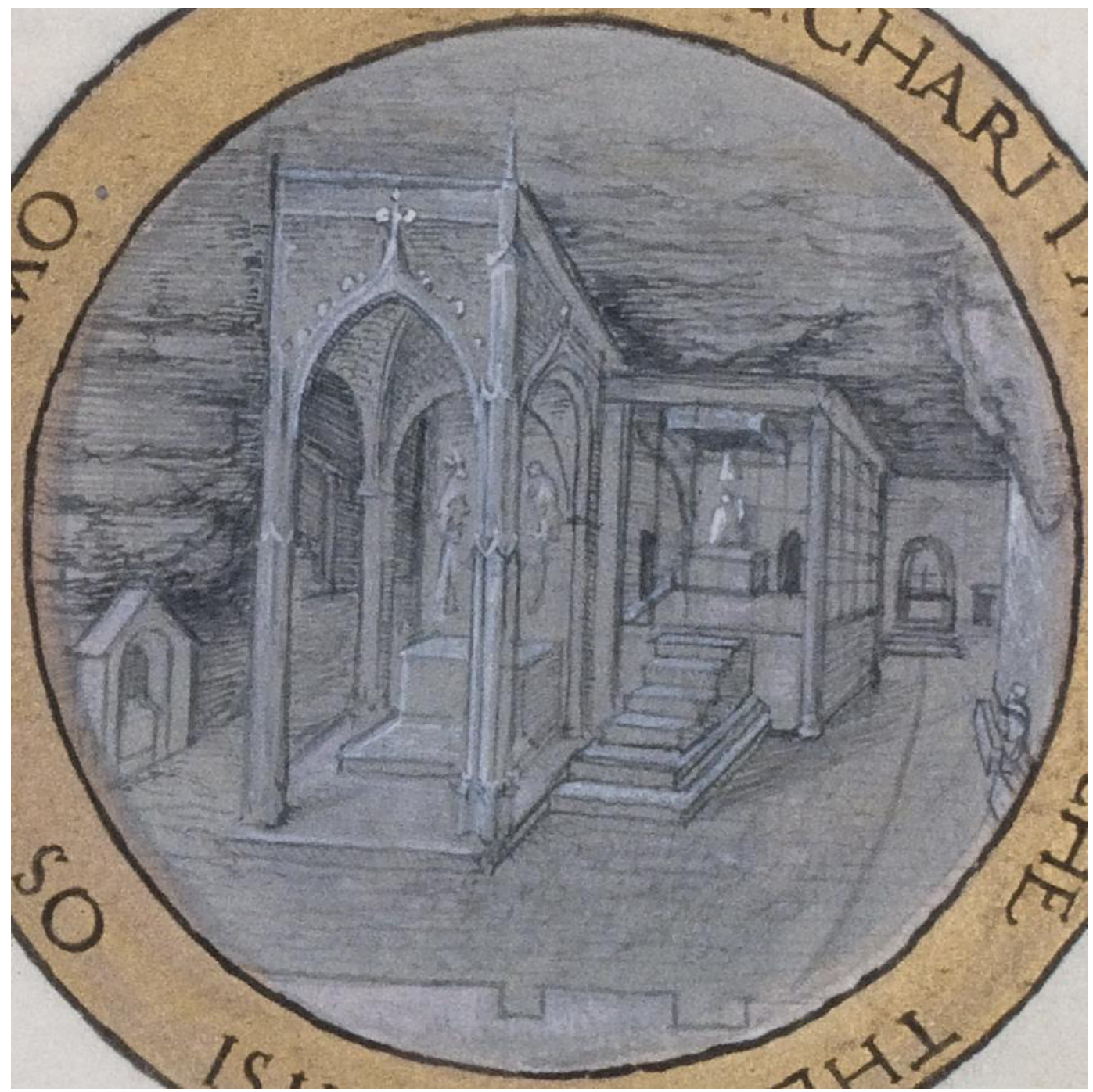

Fig. 3 : La chapelle de la grotte de la Sainte-Baume. Miniature de Godefroy le Batave, dans Vie de la Magdalene, 1517 (B.n.F.ms. Fr. 24.955. fol.63). 